\title{
Decreasing Striatopallidal Pathway Function Enhances Motivation by Energizing the Initiation of Goal-Directed Action
}

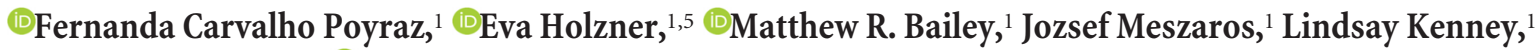 \\ Mazen A. Kheirbek, ${ }^{1,4}$ @Peter D. Balsam, ${ }^{1,5 *}$ and Christoph Kellendonk ${ }^{1,2,3 *}$ \\ ${ }^{1}$ Department of Psychiatry and 2Department of Pharmacology, College of Physicians and Surgeons, Columbia University, New York, New York 10032, \\ ${ }^{3}$ Division of Molecular Therapeutics and ${ }^{4}$ Division of Integrative Neuroscience, New York State Psychiatric Institute, New York, New York 10032, and \\ ${ }^{5}$ Barnard College, New York, New York 10027
}

Altered dopamine D2 receptor (D2R) binding in the striatum has been associated with abnormal motivation in neuropsychiatric disorders, including schizophrenia. Here, we tested whether motivational deficits observed in mice with upregulated D2Rs (D2R-OE dev $_{\text {mice) }}$ are reversed by decreasing function of the striatopallidal "no-go" pathway. To this end, we expressed the $\mathrm{G}_{\alpha \mathrm{i}}$-coupled designer receptor hM4D in adult striatopallidal neurons and activated the receptor with clozapine-N-oxide (CNO). Using a head-mounted miniature microscope we confirmed with calcium imaging in awake mice that hM4D activation by CNO inhibits striatopallidal function measured as disinhibited downstream activity in the globus pallidus. Mice were then tested in three operant tasks that address motivated behavior, the progressive ratio task, the progressive hold-down task, and outcome devaluation. Decreasing striatopallidal function in the dorsomedial striatum or nucleus accumbens core enhanced motivation in $\mathrm{D} 2 \mathrm{R}-\mathrm{OE} \mathrm{E}_{\mathrm{dev}}$ mice and control littermates. This effect was due to increased response initiation but came at the cost of goal-directed efficiency. Moreover, response vigor and the sensitivity to changes in reward value were not altered. Chronic activation of hM4D by administering CNO for 2 weeks in drinking water did not affect motivation due to a tolerance effect. However, the acute effect of $\mathrm{CNO}$ on motivation was reinstated after discontinuing chronic treatment for $48 \mathrm{~h}$. Used as a therapeutic approach, striatopallidal inhibition should consider the risk of impairing goal-directed efficiency and behavioral desensitization.

Key words: calcium imaging; DREADD; indirect pathway; motivation; striatum

\section{Significance Statement}

Motivation involves a directional component that allows subjects to efficiently select the behavior that will lead to an optimal outcome and an activational component that initiates and maintains the vigor and persistence of actions. Striatal output pathways modulate motivated behavior, but it remains unknown how these pathways regulate specific components of motivation. Here, we found that the indirect pathway controls response initiation without affecting response vigor or the sensitivity to changes in the reward outcome. A specific enhancement in the activational component of motivation, however, can come at the cost of goaldirected efficiency when a sustained response is required to obtain the goal. These data should inform treatment strategies for brain disorders with impaired motivation such as schizophrenia and Parkinson's disease.

\section{Introduction}

Motivation can be defined as the activation of goal-directed behavior. It involves a "directional" component, allowing subjects to efficiently select a behavior leading to optimal outcome, and an "activational" component that initiates and maintains the vigor and persistence of actions (Salamone, 1988; Simpson and Balsam, 2015). Different striatal subregions have been implicated in motivation, including the dorsomedial striatum (DMS) (Yin et

State Psychiatric Institute. We thank Dr. Jonathan Javitch and members of the C.K. laboratory for thoughtful discussions on the data presented in the manuscript; and Dr. Rene Hen for sharing reagents and resources. The authors declare no competing financial interests.

*P.D.B. and C.K. contributed equally to this manuscript. 
al., 2005a, b; Shiflett et al., 2010; Tai et al., 2012) and nucleus accumbens core (NAc) (Corbit et al., 2001; Nowend et al., 2001; Lex and Hauber, 2010; Mai et al., 2012). However, it remains unclear whether the activational and directional components of motivation can be dissociated (Bailey et al., 2015) and what the relative contributions of DMS and NAc are in regulating these components.

The striatum is the input nucleus of the basal ganglia (BG), which projects to BG output nuclei via two parallel pathways. The indirect pathway is formed by striatopallidal neurons that predominantly express dopamine D2 receptors (D2Rs). It projects from the dorsal striatum to the external segment of the globus pallidus (GPe) or from the NA to the ventral pallidum (VP). The latter pallidal structures further connect to BG output nuclei, the internal segment of the globus pallidus (GPi) and substantia nigra (SNr) (Gerfen and Surmeier, 2011). In contrast, the direct pathway is formed by striatonigral neurons that express dopamine D1 receptors (D1Rs) and project monosynaptically to BG output nuclei. However, this anatomical segregation is not complete because neurons expressing D1Rs also innervate the "indirect" pallidum (Fujiyama et al., 2011; Cazorla et al., 2014; Kupchik et al., 2015). Direct and indirect pathways are often described as "go" and "no-go" pathways because the former disinhibits, whereas the latter inhibits thalamocortical activity (Albin et al., 1989).

D2Rs are $\mathrm{G}_{\alpha \mathrm{i}-}$ coupled receptors that largely inhibit neuronal function. In humans, dopaminergic function and D2R binding have been linked to motivation in healthy individuals (Tomer et al., 2008) and individuals with neuropsychiatric disorders, including drug addiction (Volkow et al., 2002) and Parkinson's disease (Pedersen et al., 2009; Thobois et al., 2010). Decreased motivation is a negative symptom of schizophrenia, and brain imaging studies have shown increased availability of D2Rs in the striatum of drug-naive patients with schizophrenia (Laruelle, 1998; Abi-Dargham et al., 2000; Howes and Kapur, 2009).

Using a mouse model of selective D2R hyperfunction (D2R$\mathrm{OE}_{\mathrm{dev}}$ mice), we previously showed that striatal D2R upregulation starting in late embryonic development results in deficits in incentive motivation, replicating the negative symptoms of schizophrenia (Drew et al., 2007; Ward et al., 2009). Moreover, D2R upregulation increases excitability of striatal projections neurons by downregulating inward-rectifier potassium channels ( $\mathrm{K}_{\mathrm{ir}}$ channels) (Cazorla et al., 2012, 2014). We therefore tested whether the motivation deficit of $\mathrm{D} 2 \mathrm{R}-\mathrm{OE}_{\mathrm{dev}}$ mice could be rescued by decreasing indirect-pathway function to offset increased excitability of striatal projection neurons in these animals.

To this end, we used the designer $G_{\alpha i}$-coupled receptor hM4D, which previously had been used to decrease indirectpathway function (Ferguson et al., 2011). Using in vivo calcium imaging, we verified that acutely activating $G_{\alpha i}$-coupled signaling in striatopallidal neurons disinhibits GPe activity. At the behavioral level, inhibiting striatopallidal neurons in the DMS and NAc enhanced motivation in $\mathrm{D} 2 \mathrm{R}-\mathrm{OE}_{\mathrm{dev}}$ and control littermates by modulating initiation of the goal-directed action. However, enhanced performance on a task that requires rapid repetition of a brief action came at the cost of goal-directed efficiency in a task

Correspondence should be addressed to either Dr. Christoph Kellendonk or Dr. Peter D. Balsam, Columbia University/New York State Psychiatric Institute, 1051 Riverside Drive, New York, NY 10032. E-mail: ck491@cumc.columbia.edu or balsam@columbia.edu.

M. A. Kheirbek's present address: Department of Psychiatry, Center for Integrative Neuroscience, University of California, San Francisco, CA 94158

DOI:10.1523/JNEUROSCI.0444-16.2016

Copyright $\odot 2016$ the authors $\quad 0270-6474 / 16 / 365989-14 \$ 15.00 / 0$ that requires an action of extended duration. Despite the effects on initiation of goal-directed action, response vigor and sensitivity to changes in reward value were not affected.

Because disorders associated with impaired motivation are often chronic conditions, we also investigated the behavioral effects of chronically decreasing indirect-pathway function. Surprisingly, chronic hM4D activation did not affect motivation due to a tolerance effect that was reversed $48 \mathrm{~h}$ after drug discontinuation. These findings have important implications for drug therapies to enhance motivation by targeting GPCRs and BG circuitry.

\section{Materials and Methods}

\section{Experimental subjects}

All animal protocols used in the present study were approved by the Institutional Animal Care and Use Committees of Columbia University and New York State Psychiatric Institute. The generation of D2R-OE mice has been described previously (Kellendonk et al., 2006). TetO-D2R mice have been backcrossed for over 20 generations onto the C57BL/6] background, and CaMKII $\alpha$-tTA mice backcrossed onto the $129 \mathrm{SveVTac}$ background. To generate $\mathrm{D} 2 \mathrm{R}-\mathrm{OE}_{\mathrm{dev}}$ mice, tetO-D2R/C57BL/6 mice were crossed to CaMKII $\alpha$-tTA/129SveVTac mice. Double transgenic mice express the transgenic D2R, and these animals were crossed to Drd2-Cre (ER44Gsat/Mmcd; GENSAT) mice backcrossed to C57BL/6] to obtain the transgenic $\mathrm{D} 2 \mathrm{R}-\mathrm{OE}_{\mathrm{dev}} / \mathrm{Drd} 2$-Cre mice. For experiments that included D2R-OE ${ }_{\text {dev }}$ animals, controls were littermates of D2R$\mathrm{OE}_{\mathrm{dev}} / \mathrm{Drd2}$-Cre mice that were positive for the Cre transgene but negative for the TetO or tTa transgenes. For experiments that did not include D2R-OE $\mathrm{dev}_{\mathrm{dev}}$ mice, animals were Drd2-Cre backcrossed onto the C57BL/6J background. Both male and female adult mice at least 8 weeks old were used in this study. Mice were housed (up to 5 animals per cage) under a 12:12 h light/dark cycle in a temperature-controlled environment, and all behavioral testing was done during the light cycle. Food and water were available ad libitum, except for experiments that required restriction. Animals were food-deprived when being trained or tested in operant behavioral tasks and maintained at $85 \%$ of their baseline weight. For chronic CNO treatment, mice had ad libitum access to CNO-treated water $(0.25 \mathrm{mg} / \mathrm{ml})$ instead of regular drinking water. Animals were water-restricted for $16 \mathrm{~h}$ before experiments that involved acute oral $\mathrm{CNO}$ treatment.

\section{Stereotactic viral injections and lens implantation}

For all viral injection surgeries that did not involve lens implantation for calcium imaging, mice were anesthetized with a mixture of ketamine and xylazine $(100 \mathrm{mg} / \mathrm{kg}$ and $10 \mathrm{mg} / \mathrm{kg})$, injected intraperitoneally, and placed into a stereotaxic apparatus. For viral injection surgeries involving lens implantation for calcium imaging, mice were anesthetized by inhalation with isoflurane (3.0\% for induction, $1.0 \%$ for maintenance) mixed with oxygen $(1 \mathrm{~L} / \mathrm{min})$. For all surgeries, body temperature was maintained at $37^{\circ} \mathrm{C}$ with a heating pad. Surgical incision to expose the cranium was made, and small cranial windows $(<0.5 \mathrm{~mm})$ were drilled at the appropriate sites. The AAV5/hSyn-DIO-hM4D-mCherry virus (University of North Carolina) was used for Cre-dependent expression of the hM4D receptor at a titer of $10^{13}$ particles $/ \mathrm{ml}$. It was delivered at an average rate of $100 \mathrm{nl} / \mathrm{min}$ using glass pipettes (tip diameter $10-15 \mu \mathrm{m}$ ). All stereotactic coordinates were measured relative to bregma. A total of $0.4-0.5 \mu \mathrm{l}$ volume was delivered into each site for all injections. Two sites of injection were used for bilaterally targeting the DMS to allow diffusion of the virus to the entire region (site A: anteroposterior: $1.3 \mathrm{~mm}$, mediolateral: $\pm 1.4 \mathrm{~mm}$, dorsoventral: -3.3 ; site B: anteroposterior $0.9 \mathrm{~mm}$, mediolateral $\pm 2.0 \mathrm{~mm}$, dorsoventral $-3.4 \mathrm{~mm}$ ). The NAc was targeted bilaterally with one set of coordinates (anteroposterior: $1.7 \mathrm{~mm}$, mediolateral: $\pm 1.2 \mathrm{~mm}$, dorsoventral: $4.0 \mathrm{~mm}$ ). For all animals, except those used for calcium imaging, the skin incision was closed using tissue adhesive after viral injection, and animals were allowed to recover for 4 weeks before behavior experiments were initiated.

In mice used for calcium imaging of the GPe, after the AAV5/hSynDIO-hM4D-mCherry virus was injected into the DMS as described 
above, a $2 \mathrm{~mm}$ cranial window was drilled over the intended lens implantation site on the right hemisphere, followed by removal of the dura and aspiration of portions around the edges of the craniotomy. The AAV1/ hSyn-GCaMP6f (University of Pennsylvania Vector Core) virus was then injected into the GPe in discrete pulses, covering a $0.3 \mathrm{~mm}$ distance in the dorsoventral axis (anteroposterior $0.0 \mathrm{~mm}$, mediolateral: $1.8 \mathrm{~mm}$, dorsoventral: -3.9 to $-4.1 \mathrm{~mm}$ ). A gradient index lens, measuring $0.5 \mathrm{~mm}$ in diameter and $\sim 8.4 \mathrm{~mm}$ in length (Inscopix), was lowered into the same site used for viral injection into the GPe with alternate retractions of $0.5 \mathrm{~mm}$ for every $1 \mathrm{~mm}$ ventral increment to allow penetrated tissue to properly settle around the lens. After implantation, the portion of the lens extending above the skull was fixed in place using dental cement and anchored by 3 screws attached to different plates on the skull. The lens was covered with a silicone elastomer to protect the imaging surface from external damage, and mice were allowed to recover from surgery. The silicone elastomer was removed 4 weeks after surgery for attachment of a baseplate (Inscopix) to support the miniature microscope (Inscopix) on each animal's head. For this procedure, mice were once again anesthetized with isoflurane. The silicone mold was removed, and the miniature microscope with a baseplate attached and the $473 \mathrm{~nm}$ LED turned on was positioned above the implanted lens and lowered with a micromanipulator until fluorescence could be detected. Once the microscope was positioned for imaging at an adequate focal plane, the magnetic baseplate was cemented around the lens adjoined to the dental cement previously placed at the time of initial surgery. The microscope was subsequently detached, and a magnetic cover plate (Inscopix) was secured onto the baseplate with a screw set to protect the lens until imaging.

\section{Drug treatments}

CNO was provided by the National Institutes of Health as part of the National Institutes of Mental Health Chemical Synthesis and Drug Supply Program. For behavioral experiments, $\mathrm{CNO}$ was freshly dissolved in sterile PBS on the day of treatment. For acute treatment, the drug was prepared at $0.2 \mathrm{mg} / \mathrm{ml}$ and delivered at $2 \mathrm{mg} / \mathrm{kg}$ dose (i.p.) $30 \mathrm{~min}$ before a behavioral task, unless otherwise indicated. Saline injections for control conditions consisted of $10 \mathrm{ml} / \mathrm{kg}$ sterile PBS. Animals were kept in their home cages after injection with drug or saline before behavioral testing. For chronic treatment, CNO was dissolved in animals' regular drinking water at a concentration of $0.25 \mathrm{mg} / \mathrm{ml}$. Animals treated with $\mathrm{CNO}$ chronically had this CNO solution as their only source of drinking water ad libitum for at least 2 weeks. Except where otherwise indicated, $\mathrm{CNO}$ solution in the drinking water was freshly prepared on the day before start of chronic treatment, and freshly prepared solution was replenished as needed every $2-4 \mathrm{~d}$ for the duration of chronic treatment. Vehicle chronic treatment consisted of regular mouse drinking water. For acute oral $\mathrm{CNO}$ administration, animals were allowed to freely consume $\mathrm{CNO}$ solution in drinking water at $0.25 \mathrm{mg} / \mathrm{ml}$ for $1 \mathrm{~h}$ before behavioral testing. Crossover designs for drug treatment were used for testing in all behavioral assays, unless otherwise indicated, with animals receiving $\mathrm{CNO}$ or saline/vehicle on alternate days of testing, counterbalancing for genotype, virally targeted brain region, sex, cage, and behavior testing chamber.

\section{In vivo calcium imaging}

For calcium imaging experiments, cellular activity and locomotor activity were simultaneously measured while animals moved freely in an open field. Before each imaging session, the miniature microscope was connected to the magnetic baseplate attached to each animal's cranium and fixed in place by the baseplate screw set while the mouse was briefly anesthetized with isoflurane. Each animal was placed back into its home cage for $20 \mathrm{~min}$ to recover from anesthesia before drug injection and imaging. During imaging sessions, mice were placed in acrylic activity chambers $(42 \mathrm{~cm}$ long $\times 42 \mathrm{~cm}$ wide $\times 38 \mathrm{~cm}$ high $)<1$ min before optical recording with the miniature microscope was initiated. The Ethovision XT system (Noldus) was used to trigger both start and end of recording sessions using a TTL pulse converter. This software was also used to track each animal's locomotor activity using a video camera placed over the open field area. On a single day of testing, an animal was subjected to two imaging session starting $30 \mathrm{~min}$ after acute treatment with saline or CNO. Drug treatments for paired session in one day consisted of either two sessions after saline treatment or one session after treatment with saline followed by a session after treatment with CNO. During each imaging session, calcium activity was recorded over a total of $5 \mathrm{~min}$.

\section{Calcium imaging data processing and statistical analysis}

Calcium imaging recordings were acquired at 20 frames per second, and independent cellular units were identified and processed using Mosaic software (Inscopix). Briefly, videos were spatially and temporally binned by a factor of 4 , motion corrected, and independent cellular units were identified. First, movies were spatially down-sampled by a factor of 4 . To correct for brain movement, all frames in movie sequences acquired from the same mouse at the same focal plane were registered to one single frame and concatenated in time. To normalize fluorescence signals to the average fluorescence of the entire frame, we used the mean $z$-projection image of the entire movie as reference $(\mathrm{F})$ to generate a movie representing percentage-change-over-baseline $(\Delta \mathrm{F} / \mathrm{F})$. Calcium transients from individual cells were isolated and identified with an automated cellsorting algorithm that uses independent and principal component analyses of each $\Delta \mathrm{F} / \mathrm{F}$ movie. The independent components identified by the algorithms were visually inspected for spatial configuration, and temporal properties of calcium traces and those that appeared like calcium transients from individual cell bodies were used for further analysis. Histograms for the average calcium activity of all cells imaged from one mouse at the same focal plane were generated for different drug conditions: after treatment with either saline or $\mathrm{CNO}$ or after two treatments with saline. Student's $t$ tests for paired data were used to compare calcium activity between drug conditions. In addition, calcium transients from individual cells imaged over 5 min during different drug conditions were separated into $12 \mathrm{~s}$ time bins. For individual cell analysis, average calcium activity in $12 \mathrm{~s}$ bins measured for each individual cell at the same focal plane, after treatment first with saline and then with $\mathrm{CNO}$ or after two treatments with saline, were also compared using Student's $t$ tests for paired data. Cells that displayed a significant increase or decrease in activity in between sessions were identified, and the proportions of cells that became significantly more active or less active were compared using a $\chi^{2}$ test to determine whether these proportions were different from what would be expected by chance.

\section{Behavioral assays: operant training and progressive ratio task}

All mice that underwent testing in the progressive ratio task started initial lever press training at least 2 weeks after viral injection surgery, and testing in the progressive ratio task occurred at least 4 weeks after surgery. Training and testing were done in experimental chambers equipped with liquid dippers, retractable levers, a head entry detector in the food magazine, a house light, and an exhaust fan. Unless otherwise indicated, for every session, the dipper was submerged into a tray containing evaporated milk so that raising the dipper provided a reward of one $0.01 \mathrm{ml}$ drop of evaporated milk into the feeder trough.

Dipper training. For the first phase of training, animals learned to retrieve the milk reward from the feeder trough. Mice were placed inside the chambers with the dipper in the raised position, providing access to a drop of evaporated milk. The dipper was retracted $10 \mathrm{~s}$ after the first head entry into the feeder trough. A variable intertrial interval between 1 and $108 \mathrm{~s}$ ensued, followed by a new trial identical to the first. The session ended after $30 \mathrm{~min}$ or 20 dipper presentations. On the following day, mice underwent another session similar to the first, except that the dipper retraction was response-independent. During each trial, the dipper was raised for $8 \mathrm{~s}$ and then lowered independently of whether mice had made a head entry. The session ended after $30 \mathrm{~min}$ or 20 dipper presentations. All mice underwent dipper training for $2 \mathrm{~d}$ before moving on to Pavlovian training.

Pavlovian (auto-shaping) training. During the $1 \mathrm{~h}$ Pavlovian training session, the lever was extended into the chamber for $6 \mathrm{~s}$ and immediately followed by a $5 \mathrm{~s}$ dipper presentation to allow mice to associate the lever extension with the milk reward. Each pairing was separated by a variable intertrial interval averaging $60 \mathrm{~s}$, and dipper presentation always occurred at the termination of lever presentation, independent of whether or not a lever press occurred. 
Continuous reinforcement training. In the subsequent phase of training, mice were required to press a lever to earn the reward. At the beginning of the session, the lever was extended into the chamber, and every lever press was reinforced. In this and all subsequent sessions, the reward consisted of raising the dipper with a drop of evaporated milk in it for $5 \mathrm{~s}$. The lever was retracted after every two times the mouse earned a reward and then was reextended after a variable intertrial interval, averaging $30 \mathrm{~s}$. The session ended when the mouse earned 60 reinforcements or $1 \mathrm{~h}$ elapsed. Mice continued to undergo daily continuous reinforcement sessions until they earned 60 rewards in two consecutive sessions. When all mice reached criterion, they were moved to random interval (RI) schedules.

RI training. In RI schedule training, the lever remained extended throughout the session, but lever presses were not reinforced until after a random interval had elapsed. The average time between one reinforcer and the time at which the next one can be earned is defined by the RI schedule. All mice began on the RI 3 s schedule, meaning that a lever press was reinforced only after $3 \mathrm{~s}$ on average elapsed from the start of a session or from the time of the last reward. When a mouse earned at least 40 rewards in one session, the RI schedule was increased. The RI schedules used were $3,10,15$, and $20 \mathrm{~s}$. When all mice reached the criterion of 40 rewards in one session on the RI 20 s schedule, they began experimental testing on a progressive ratio schedule. Mice continued to undergo RI $20 \mathrm{~s}$ sessions for $1-2 \mathrm{~d}$ in between each progressive ratio session to prevent lever pressing behavior from being extinguished after not earning many rewards in progressive ratio sessions.

Progressive ratio task. The progressive ratio task directly assays operant motivation by quantifying the amount of effort a subject is willing to expend to earn a reward. The program was designed so that the first reward was earned after two presses and the number of presses required to obtain each successive reward increased geometrically by doubling after each reward. Each session could last up to $2 \mathrm{~h}$ but ended early if the mouse did not press the lever for 3 min. Motivation was measured by recording the number of rewards earned during a session, the total number of lever presses made in a session, the breakpoint, or ratio requirement at which animals stopped responding in a session, as well as the session duration, or how long a subject continued to respond before giving up in a session.

\section{Progressive hold-down task}

Following the progressive ratio, all mice were tested in the progressive hold-down task (Bailey et al., 2015) in which rewards could be earned by continuously holding the lever in a depressed position for a criterion duration. Specific training for the progressive hold-down test consisted of variable interval hold-down (VIH) schedules. Each VIH session involved up to 40 trials. At the beginning of each trial, the required hold duration was drawn randomly from a distribution with a mean specified by the session. Each session ended when a mouse successfully completed 40 trials or when $1 \mathrm{~h}$ elapsed. This hold requirement remained in place until the subject was reinforced for completing the trial. During the first session, the distribution of required hold durations had a mean of $0.5 \mathrm{~s}$ (VIH $0.5 \mathrm{~s}$ ). When all mice in the cohort earned 40 rewards in one session, they were moved to the subsequent VIH schedule, following the sequence VIH $0.5,1,2,4,6,8$, and $10 \mathrm{~s}$. Animals were only tested in the progressive hold-down test after all subjects in the cohort were able to complete all 40 trials in VIH $10 \mathrm{~s}$ schedule. For the progressive holddown task, the first required hold duration was fixed at $3 \mathrm{~s}$, and the requirement for subsequent hold durations was increased sequentially by a factor of 1.4. The sessions could last up to $2 \mathrm{~h}$ but ended early if the mouse did not press the lever for $10 \mathrm{~min}$. Motivation was assayed by measuring the number of lever presses made, how long subjects continued to respond in a session, and the number of rewards earned in a session.

\section{Outcome devaluation}

In this task, mice were tested for their sensitivity to alterations in reward value. For example, a manipulation that facilitates habit formation or it makes animals less sensitive to within-session changes of reward value by satiation ought to be reflected in a diminished impact of explicitly deval- uing the reinforcer. The milk reward was devalued by allowing mice to have unlimited access to milk for $30 \mathrm{~min}$ before operant testing. As a control, on different days, mice were given unlimited access to standard mouse chow for $1 \mathrm{~h}$ before testing. Mice were acutely treated with either $\mathrm{CNO}$ or saline $1 \mathrm{~h}$ after the start of prefeeding. Thirty minutes after the drug administration, mice were placed in an operant chamber with an extended lever for $15 \mathrm{~min}$, but lever presses were not reinforced throughout the session. Testing occurred on 4 different days in a randomized design so that each mouse received each experimental manipulation once ( prefeeding with milk or chow and drug treatment with either $\mathrm{CNO}$ or saline). The number of lever presses made in each session was measured for assessment of outcome devaluation. Because this nonreinforced test extinguished pressing behavior, mice were trained in random ratio sessions for 2-3 d in between devaluation testing days to maintain high rates of lever pressing. In a random ratio schedule, there is a constant probability of reinforcement for each lever press. The specific schedule used, random ratio 20 , required the animal to press the lever on average 20 times before receiving a reward.

\section{Open field}

For open-field experiments that did not involve calcium imaging (described above), exploration and reactivity to an open field was assayed in acrylic activity chambers $(42 \mathrm{~cm}$ long $\times 42 \mathrm{~cm}$ wide $\times 38 \mathrm{~cm}$ high) equipped with infrared photobeams for motion detection (Kinder Scientific). Mice were placed in the open field, and activity was automatically recorded for a specified amount of time (90 or $120 \mathrm{~min}$ ). For experiments involving acute drug administration, the open-field system was programmed to pause recording $30 \mathrm{~min}$ after the start, at which point mice were administered $\mathrm{CNO}$ or saline and placed back in the open field. Recording of locomotor activity resumed immediately after acute drug injections. For open-field experiments involving acute oral administration of $\mathrm{CNO}$ (data not shown), animals were water-deprived and allowed to freely consume CNO-treated or untreated water for $1 \mathrm{~h}$ immediately before being placed in the open field. Each animal was subjected to three total sessions, including control sessions, on different days. In one session, animals were given untreated water before testing; in another session, animals were given freshly prepared $\mathrm{CNO}$-treated water before testing. In yet another session, animals were given $\mathrm{CNO}$-treated water that had been prepared 1 month prior and stored at room temperature (1 mo old CNO works as well as freshly prepared CNO; data not shown).

\section{Histology and microscopy}

For all histological analysis of brain tissue following behavioral experiments, mice were anesthetized with a mixture of ketamine and xylazine $(100 \mathrm{mg} / \mathrm{kg}$ and $10 \mathrm{mg} / \mathrm{kg}$, respectively) injected intraperitoneally and transcardially perfused, first with PBS and then with $4 \%$ PFA. Following perfusion, brains were postfixed in 4\% PFA for $24 \mathrm{~h}$ and then transferred to PBS. Brains were then sliced into $50 \mu \mathrm{m}$ sagittal or coronal sections using a vibratome, and every section was collected. Immunohistochemistry using fluorescence was performed on these free-floating sections by treating sections first with blocking buffer $(0.5 \%$ BSA, 5\% horse serum, $0.2 \%$ Triton X-100), followed by overnight incubation with one or more primary antibodies and subsequently with the appropriate secondary antibodies conjugated to a fluorophore. The primary antibodies used included rabbit anti-dsRed (1:250, Clontech, catalog \#632496), mouse anti-RFP (1:1000, Abcam, catalog \#AB65856), rabbit anti-Cre (1:2000) (Kellendonk et al., 1999), and goat anti-ChAT (1:100, Millipore, catalog \#AB144P). Sections were washed with $0.2 \%$ Triton X-100 in between primary and secondary antibody incubations and with $50 \mathrm{~mm}$ Tris-Cl, $\mathrm{pH}$ 7.4, before mounting. Sections were mounted on glass slides and subsequently coverslipped for imaging with VectaShield containing DAPI (Vector Labs). For confirmation of spread of viral infection in targeted structures, images were acquired at $2.5 \times$ magnification using a Hamamatsu camera attached to a Carl Zeiss epifluorescence microscope. For analysis of coexpression of fluorescent and immune-labeled proteins, images were acquired at $20 \times$ or $40 \times$ using a Nikon Ti Eclipse inverted microscope for scanning confocal microscopy. Micrographs were processed using ImageJ software (National Institutes of Health). 
Behavioral data processing and statistical analysis

All data collected in the current study were processed with Excel (Microsoft) or with custom scripts and functions written with MATLAB (The MathWorks). Statistical analyses were done with Prism 5 (GraphPad). All statistical tests were two-tailed, and $\alpha$ level was set to 0.05 . For operant tests of motivation, the behavioral measures used for analysis included the total number of lever presses and reinforcers earned in a session, as well as the session duration, for the progressive ratio and progressive hold-down tests. For outcome devaluation tests, total number of lever presses made in a session was the parameter analyzed. To compare normally distributed parameters, such as reinforcers earned, number of lever presses, and breakpoint, under different conditions, repeated-measures ANOVA tests were used to test for statistical significance. The log-rank Mantel-Cox test, a nonparametric statistical test, was used to compare whether or not the independent variables significantly affected session duration. To analyze the effect of drug on locomotor activity in an open field, the sums of the total ambulatory distance from a time point 30 min after intraperitoneal injection until the end of each session were obtained. These measures obtained under different conditions were used to test for statistical significance between groups using repeated-measures ANOVA tests. Alternatively, we calculated the distance traveled per minute $30 \mathrm{~min}$ after intraperitoneal injection as a percentage of baseline distance traveled per minute before acute treatment. We then performed two-way ANOVAs to compare locomotor response to acute treatment between groups.

\section{Results}

\section{Activating hM4D receptors in indirect-pathway medium spiny neurons (MSNs) leads to increased neuronal activity in GPe}

We first verified in vivo that the hM4D designer receptor can be used to inhibit striatopallidal spiny neurons. Previous work in brain slices has shown that activating hM4D receptors in D2Rpostive MSNs in the NAc decreases evoked IPSCs in the VP after optogenetic stimulation of the indirect pathway (Bock et al., 2013). We therefore hypothesized that decreasing function of the indirect pathway using the hM4D/CNO system should disinhibit neuronal activity in the GPe in vivo. To test this hypothesis, we injected a GCaMP6f virus in the GPe and a Cre-dependent hM4D virus in the DMS of Drd2-Cre mice and further implanted a microlens in the GPe (Fig. 1A). We then imaged activity of cells in the GPe in three freely behaving animals after acutely treating these animals with $\mathrm{CNO}$ or saline. Figure $1 B$ shows sample calcium traces for 10 neurons imaged after treatment with saline or $\mathrm{CNO}$, illustrating the activity of individual GPe cells in response to each drug condition.

We performed two different statistical analyses to test for the effect of CNO on the activity of GPe neurons. First, the average calcium activity over 5 min of the same cells imaged during different drug conditions was compared directly. As a control, comparison of average activity of cells imaged after two consecutive saline conditions (SAL-SAL) revealed a small decrease in activity in the second session compared with the first session $\left(t_{(210)}=\right.$ $2.308, p=0.0220, n=211$ ) (Fig. $1 C$ ). In contrast, comparison of the average activity of cells imaged first after saline treatment and then after $\mathrm{CNO}$ treatment (SAL-CNO) showed a robust increase in activity after CNO treatment compared with saline treatment $\left(t_{(208)}=6.857, p<0.0001, n=209\right)$ (Fig. 1D). Increased GPe cell activity after treatment with $\mathrm{CNO}$ was observed for all 3 mice imaged (SAL-SAL experiments: mouse 1: $t_{(102)}=0.2217, p=$ $0.8250, n=103$ cells; mouse $2: t_{(39)}=1.329, p=0.1917, n=40$ cells; and mouse $3: t_{(68)}=2.577, p=0.0121, n=69$ cells; SALCNO experiments: mouse 1: $t_{(97)}=4.803, p<0.0001, n=98$; mouse 2: $t_{(49)}=3.755, p=0.0005, n=50$; and mouse $3: t_{(60)}=$ 3.225, $p=0.0020, n=61)$.
Second, we confirmed these findings by obtaining the average activity of each cell in $12 \mathrm{~s}$ bins and analyzing the proportion of cells that showed significantly increased or decreased activity after each drug condition. For this analysis, we found in the SALSAL control condition that $3.37 \%$ of cells showed significantly increased activity and $3.79 \%$ of cells displayed significantly decreased activity in the second SAL session (SAL-SAL, 211 cells from 3 animals) (Fig. $1 C$, inset). In contrast, similar analysis for the SAL-CNO experiments showed that $10.05 \%$ of cells imaged displayed significantly increased activity, whereas only $0.48 \%$ of cells showed significantly decreased activity in the CNO session compared with the SAL session (SAL-CNO, 209 cells from 3 animals; Fig. $1 D$, inset). Analysis of these proportions for SAL-SAL and SAL-CNO experiments demonstrated that the frequency of cells showing increased activity after CNO treatment was greater than expected by chance $\left(\chi_{(2)}^{2}=8.889, p=0.0117\right)$. These findings demonstrate that activation of the $G_{\alpha i}$-coupled receptor hM4D in indirect-pathway MSNs enhances GPe activity.

\section{Decreasing function of the indirect pathway increases motivation in D2R-OE $\mathrm{dev}_{\text {and control littermates }}$}

We then analyzed the effects of inhibiting indirect pathway neurons of $\mathrm{D} 2 \mathrm{R}-\mathrm{OE}_{\mathrm{dev}}$ and control mice on motivated behavior. We expressed hM4D in the DMS and NAc because both subregions of the striatum are known to support motivated behavior (Corbit and Balleine, 2011; Hilario et al., 2012; Burton et al., 2015) (Fig. $2 A, B)$. No fluorescence signal was observed in the brain structures targeted by the direct pathway, the SNr and GPi (data not shown). Costaining for hM4D and Cre revealed that $95 \%$ of hM4D-positive cells were immune-positive for Cre recombinase. Efficiency of transfection and recombination were high, as $86 \%$ of Cre-positive cells within the constraints of the virally infected region were immune-positive for hM4D ( $n=150 / 175$ Crepositive cells from 4 mice). Cholinergic interneurons that represent $\sim 2 \%$ of neurons in the striatum are also known to express D2Rs (Dawson et al., 1990). We found that only 5\% of neurons positive for ChAT, a marker for cholinergic interneurons, were also immune-positive for hM4D in the virally infected region ( $n=6 / 110$ ChAT-positive neurons from 4 mice), in agreement with previous results using this BAC transgenic Cre mouse line (Kravitz et al., 2010; Gallo et al., 2015).

Mice were then tested in a progressive ratio schedule of reinforcement, which measures how much effort an animal is willing to expend to obtain a reward. As previously reported, D2R-OE mice showed a deficit in the progressive ratio task (Drew et al., 2007), as they stopped responding sooner than control littermates $\left(\chi_{(1)}^{2}=4.235, p=0.0121\right.$; Fig. $\left.2 C\right)$, earned fewer rewards $\left(t_{(20)}=2.692, p=0.0140\right.$; Fig. $\left.2 D\right)$, had a lower breakpoint $\left(t_{(20)}=2.535, p=0.0197\right.$; Fig. $\left.2 E\right)$, and made fewer lever presses $\left(t_{(20)}=2.846, p=0.0100\right.$; Fig. $\left.2 F\right)$. We then retested the animals after treatment with saline or CNO using a withinsubject design in which animals received treatment with saline or $\mathrm{CNO}$ on alternate days of testing. We found that both $\mathrm{D} 2 \mathrm{R}-\mathrm{OE} \mathrm{E}_{\mathrm{dev}}$ and control mice continued to respond for significantly longer times during a session after treatment with $\mathrm{CNO}$ compared with treatment with saline $\left(\mathrm{D} 2 \mathrm{R}-\mathrm{OE}_{\mathrm{dev}}: \chi_{(1)}^{2}=19.56, p<0.0001\right.$; Control: $\chi_{(1)}^{2}=9.671, p=0.0019$; Figure $\left.2 G\right)$. Both D2R-OE $\mathrm{dev}_{\mathrm{dev}}$ and control mice earned more reinforcers after treatment with $\mathrm{CNO}$ compared with saline $\left(F_{\operatorname{drug}(1,22)}=65.49, p<0.0001\right.$, $F_{\text {genotype }(1,22)}=7.526, p=0.0119, F_{\text {interaction }(1,22)}=2.285, p=$ 0.1448 ; Figure $2 G$ ). Consistent with these results, both D2R$\mathrm{OE}_{\mathrm{dev}}$ and control animals also had a higher breakpoint $\left(F_{\text {drug }(1,22)}=55.87, p<0.0001, F_{\text {genotype }(1,22)}=10.87, p=0.0033\right.$, 
A
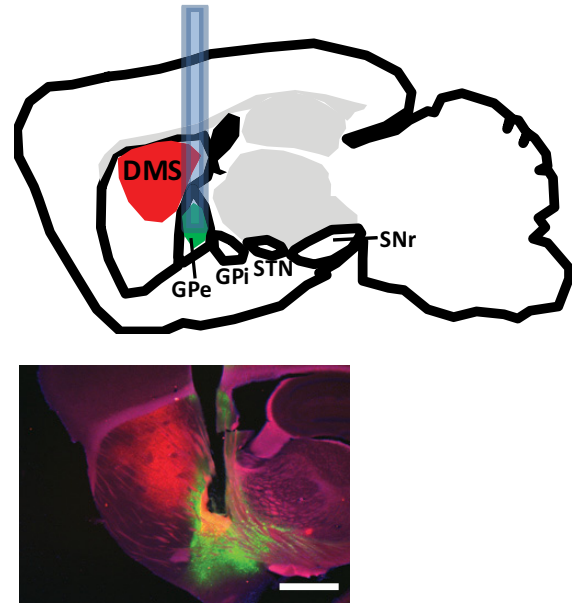

C

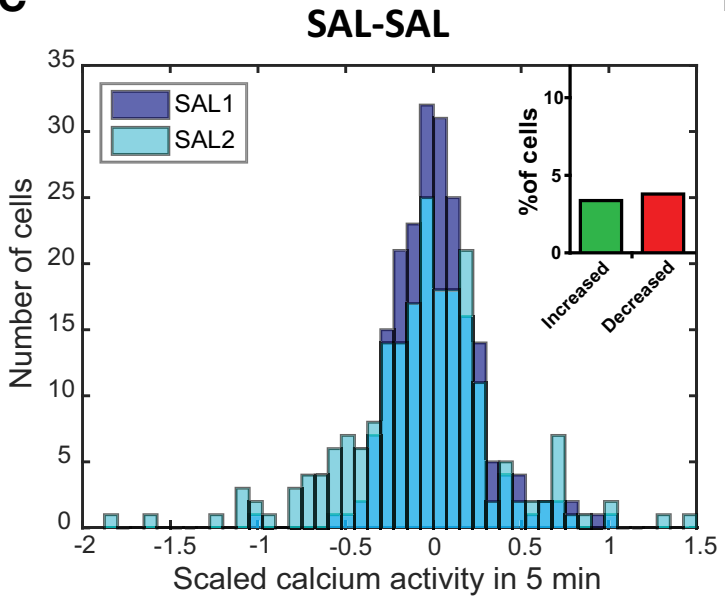

B

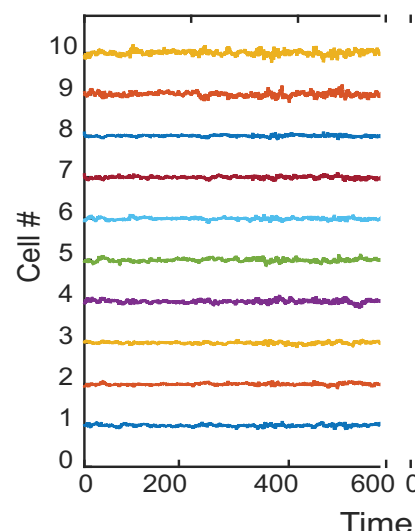

Time (s)

D

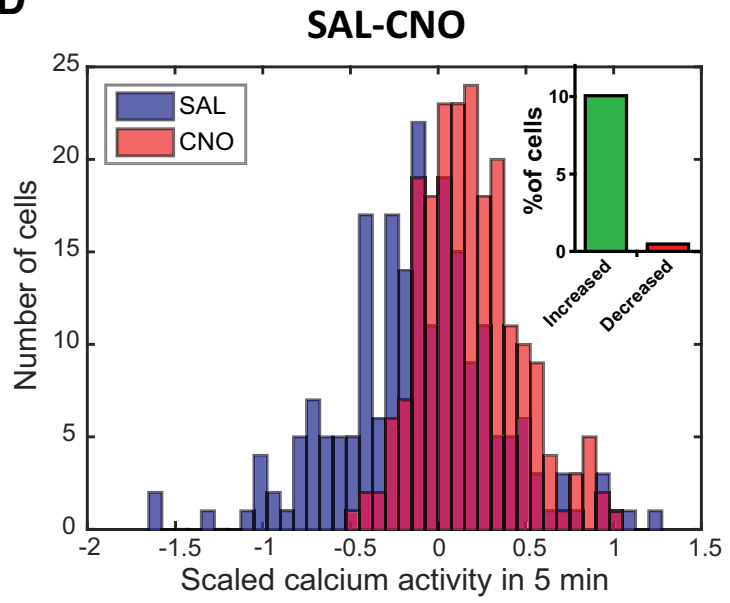

Figure 1. Activating hM4D receptors in indirect-pathway MSNs leads to increased neuronal activity in GPe. A, Top, Diagram of coronal section showing targeted injection sites in DMS and GPe for calcium imaging. Bottom, Micrograph of sagittal section showing region in the DMS and GPe virally targeted for in vivo calcium imaging of GPe cells expressing GCaMP6f (green) and indirectpathway MSNs in the DMS expressing hM4D (red). Both red and green fluorescence can be observed in the GPe, corresponding to axon terminal fields of indirect-pathway MSNs expressing hM4D and GPe cell bodies expressing GCaMP6f, respectively. The lens was implanted in the GPe for imaging using a miniature microscope, and the track of the lens can be seen in the tissue ending at the level of the GPe. Scale bar, $1 \mathrm{~mm}$. B, Representative scaled calcium traces $(\Delta \mathrm{F} / \mathrm{F})$ for 10 isolated GPe neurons imaged in a freely behaving mouse 30 min after treatment with saline and 30 min after treatment with CNO (SAL-CNO), in two separate 600 s imaging sessions, conducted on the same day without subjecting animals to anesthesia in between sessions. The scaling factors used for representative cell traces $1-10$ were $0.12,0.18,0.45,0.29,0.17,0.41,0.30,0.86,0.13$, and 0.26 , respectively. $\boldsymbol{C}, \boldsymbol{D}$, Histograms of average calcium activity for all cells imaged in $(\boldsymbol{C})$ control SAL-SAL experiments, revealing a small decrease in activity in the second session compared with the first session $\left(t_{(210)}=2.308, p=0.0220, n=211\right)$, and (D) SAL-CN0 experiments, showing a robust increase in activity after CNO treatment compared with saline treatment $\left(t_{(208)}=6.857, p<0.0001, n=209\right)$. Insets, Plots of percentage of cells that showed a significant decrease (red) or increase (green) in activity when ( $\boldsymbol{C}$, inset) comparing control paired sessions done after treatment with saline (SAL-SAL condition: 3.37\% significantly increased, 3.79\% significantly decreased), and ( $\boldsymbol{D}$, inset) comparing sessions done after treatment with saline to sessions after treatment with CNO (SAL-CNO condition: $10.05 \%$ significantly increased, $0.48 \%$ significantly decreased). A significant increase in the proportion of cells that showed increased activity can be attributed to CNO treatment when comparing proportions across conditions $(p=0.0117)$. A total of 211 cells for the SAL-CNO condition and 209 cells for the SAL-SAL condition from 3 different animals were used to calculate all statistics reported above.

$F_{\text {interaction(1,22) }}=10.23, p=0.0041$; Figure $\left.2 I\right)$ and showed increased total number of lever presses in sessions after CNO treatment compared with saline treatment $\left(F_{\text {drug }(1,22)}=69.21, p<\right.$ $0.0001, F_{\text {genotype }(1,22)}=7.912, p=0.0101, F_{\text {interaction }(1,22)}=7.528$, $p=0.0119$; Figure $2 J)$. However, while $\mathrm{CNO}$ robustly enhanced motivation in both groups, D2R-OE $\mathrm{dev}_{\mathrm{d}}$ mice still displayed decreased performance in the task compared with control littermates while on the drug, as measured by how long animals continued to respond in the task (CNO condition: $\chi_{(1)}^{2} 10.49, p=$ 0.0012; Fig. $2 G$ ), the number of reinforcers earned (Bonferroni post hoc test, $p<0.01$; Fig. $2 H$ ), the breakpoint (Bonferroni post hoc test, $p<0.001$; Fig. $2 I$ ), and the total number of lever presses made (Bonferroni post hoc test, $p<0.001$; Fig. $2 J$ ). Moreover, although mice in both groups showed enhanced performance in the progressive ratio task after $\mathrm{CNO}$ treatment, this enhancement cannot be attributed to a general increase in response vigor because, for each ratio requirement, mice in both groups showed unaltered press rates after treatment with $\mathrm{CNO}$ compared with saline $\left(F_{(1,44)}=1.894, p=0.1446\right.$; Fig. $\left.2 K\right)$.

Optogenetic stimulation and genetic lesion studies suggest that D2-MSNs inhibit motor activity (Kravitz et al., 2010; Durieux et al., 2012; Lenz and Lobo, 2013; Cazorla et al., 2014). Thus, we hypothesized that inhibiting indirect-pathway MSNs in the DMS and NAc by acutely activating hM4D receptors would energize motor behavior. To test this hypothesis, we tracked open-field locomotion of D2R-OE $\mathrm{dev}_{\mathrm{d}}$ and control littermates expressing hM4D in indirect-pathway MSNs before and after treatment with $\mathrm{CNO}$ or saline. We found that both $\mathrm{D} 2 \mathrm{R}-\mathrm{OE}_{\mathrm{dev}}$ and control littermates showed increased ambulation after treatment with $\operatorname{CNO}\left(F_{(1,22)}=32.36, p<0.0001\right)$, which peaked $\sim 30$ min 
A

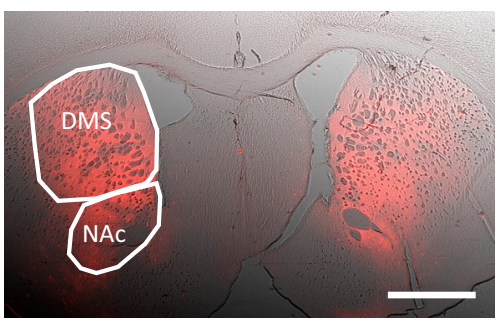

C

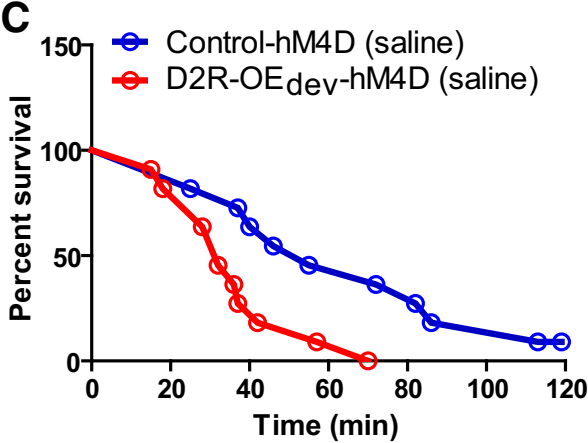

G
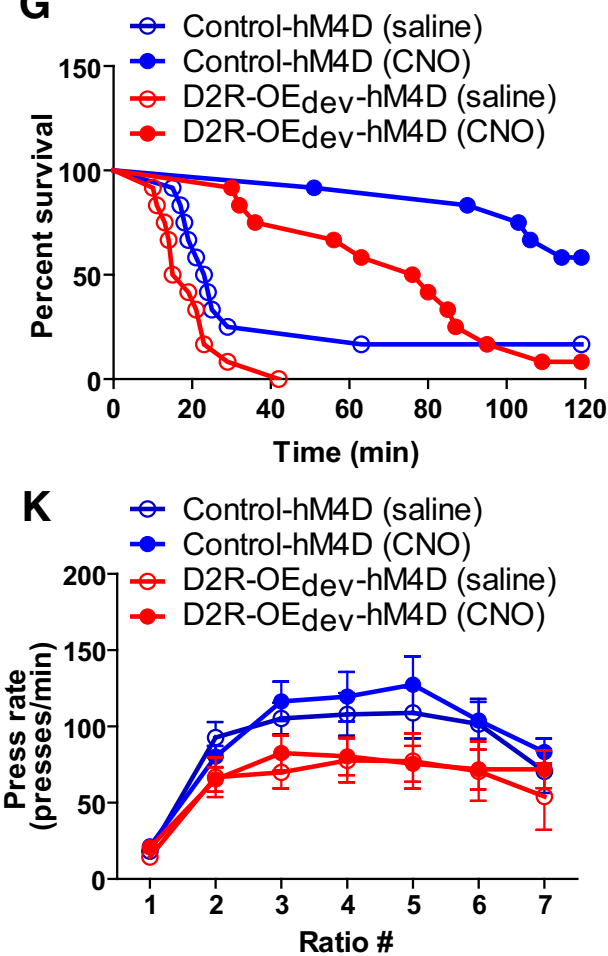

B

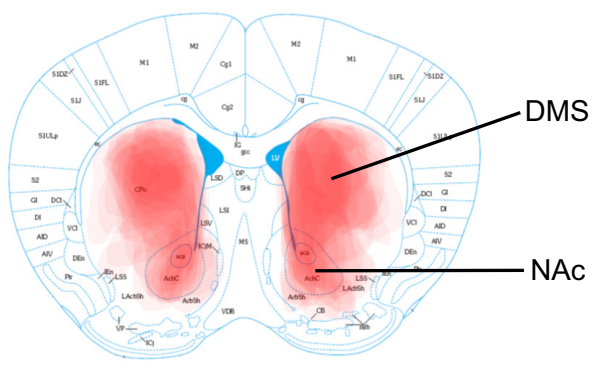

D

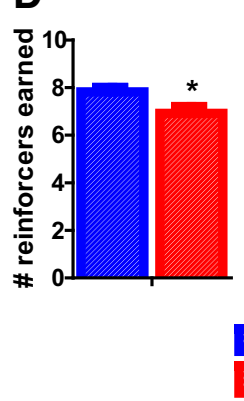

E

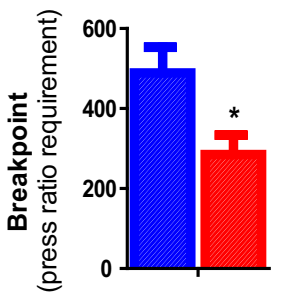

F

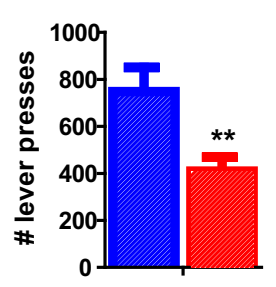

Control-hM4D (saline)

D2R-OE ${ }_{d e v}-h M 4 D$ (saline)

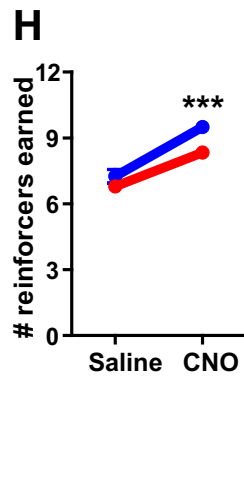

I

L

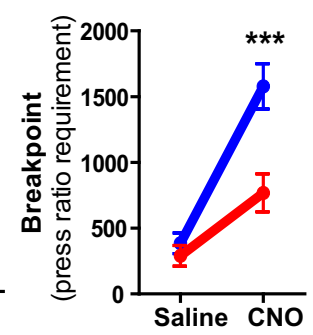

J

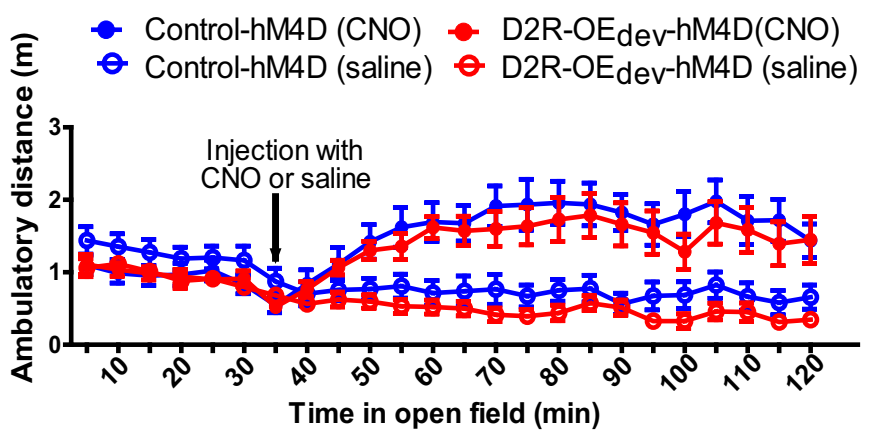

Figure 2. Decreasing function of the indirect pathway increases motivation in $D 2 R-0 E_{\text {dev }}$ and control littermates. $A$, Coronal section micrograph showing hM4D-mCherry expression in the DMS and NAc of a Drd2-Cre mouse. Scale bar, $1 \mathrm{~mm}$. B, Superimposed traces of viral spread from coronal sections at $\sim 1.0 \mathrm{~mm}$ anterior to bregma for all animals (D2R-0 $\mathrm{E}_{\text {dev }}$ and control littermates) injected with the AAV5/hSyn-DI0-hM4D-mCherry virus into the DMS and NAc. Traces were overlaid onto a diagram of the corresponding coronal section adapted from Paxinos' mouse brain atlas (Franklin and Paxinos, 2008). C, D2R-0 $\mathrm{E}_{\text {dev }}$ mice expressing $\mathrm{hM} 4 \mathrm{D}$ and injected with saline showed a decreased performance in the progressive ratio task compared with control littermates, measured by survival functions for session duration $(p=0.012)(\boldsymbol{C})$, total number of reinforcers earned $(p=0.014)(\boldsymbol{D})$, breakpoint $(p=0.0197)(\boldsymbol{E})$, and total number of lever presses made $(p=$ $0.0100)(\boldsymbol{F}) . \mathbf{G}-J$, Both D2R-0E $\mathrm{E}_{\mathrm{dev}}$ and control mice expressing hM4D in indirect-pathway MSNs in the DMS and NAc showed enhanced performance in a second session of the progressive ratio task after treatment with CNO compared with saline, measured by survival functions for session duration (D2R-0 $\mathrm{E}_{\text {dev }}: p<0.0001$; control: $\left.p=0.0019\right)(\boldsymbol{G})$, total number of reinforcers earned ( $p<$ $0.0001)(\boldsymbol{H})$, breakpoint $(p<0.0001)(\boldsymbol{I})$, and total number of lever presses made $(p<0.0001)(\boldsymbol{J})$ for each session. When comparing performance across genotypes after treatment with $C \mathrm{~N} 0$ in the progressive ratio task, $\mathrm{D} 2 \mathrm{R}-0 \mathrm{E}_{\mathrm{dev}}$ continued to respond in the task for shorter times $(p=0.0012)(\boldsymbol{G})$, earned fewer reinforcers $(p<0.01)(\boldsymbol{H})$, had a lower breakpoint $(p<0.001)(\boldsymbol{I})$, and made fewer total lever presses $(p<0.001)(J)$ per session compared with control littermates. $\boldsymbol{K}$, Analysis of animals' press rate per ratio requirement shows that subjects of either genotype did not exhibit a general increase in rate of pressing when treated with $\mathrm{CNO}$ compared with saline $(p=0.1446)$. $L$, Plot of locomotion in an open field across time showed that both D2R-0 $\mathrm{E}_{\text {dev }}$ and control mice increased ambulatory activity after treatment with CNO compared with treatment with saline $(p<0.0001)$. The increase in locomotion reached maximum level $\sim 30$ min after injection with CNO for mice of both genotypes. No difference was observed between D2R-0 $E_{\text {dev }}$ and control littermates in their response to $C N 0$ treatment $(p=0.2513)$. Data from 12 animals per genotype were used to calculate all statistics reported above using a crossover design. Error bars indicate SEM. ${ }^{*} p \leq 0.05,{ }^{* *} p \leq 0.01,{ }^{* * *} p \leq 0.001$. 
A
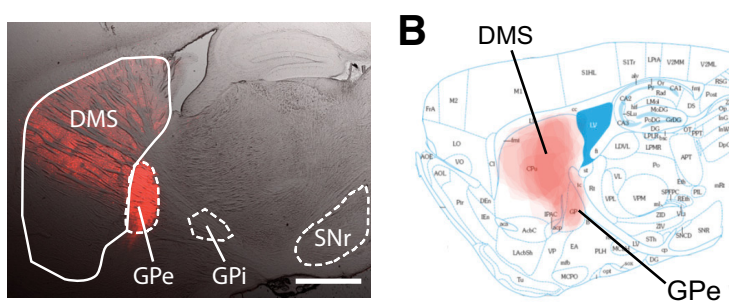

E

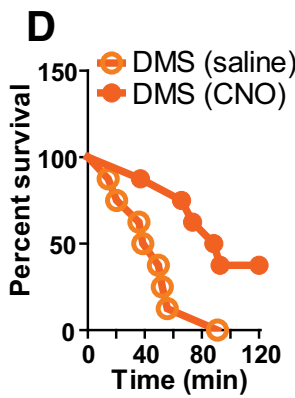

)

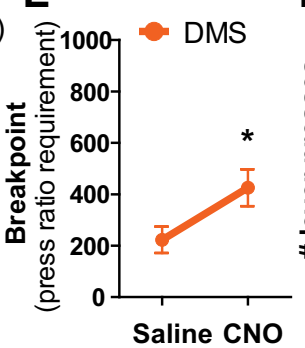

$\mathbf{F}$
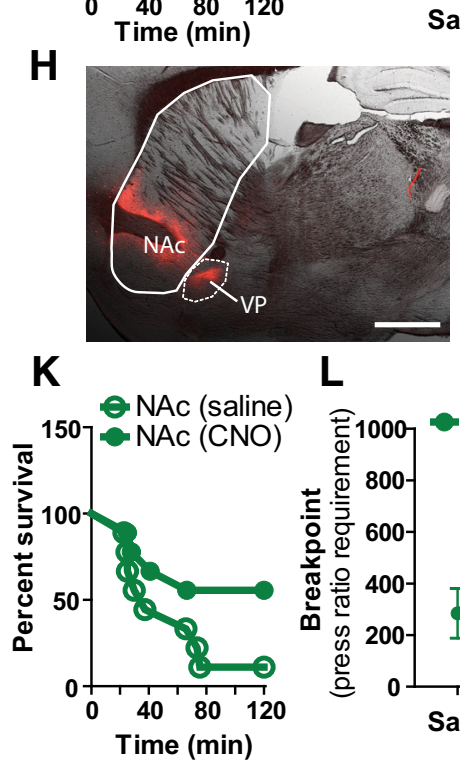

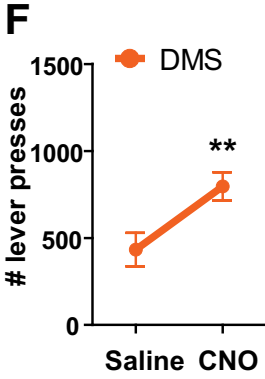

I

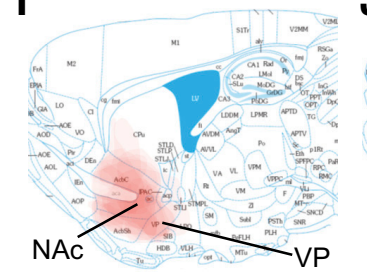

M
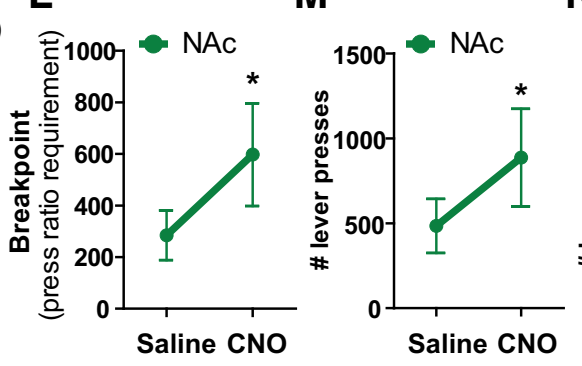

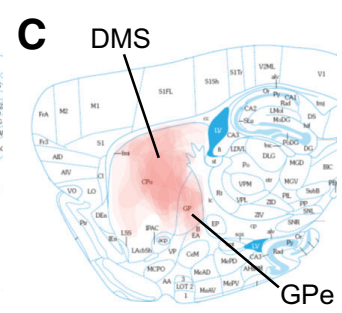

G

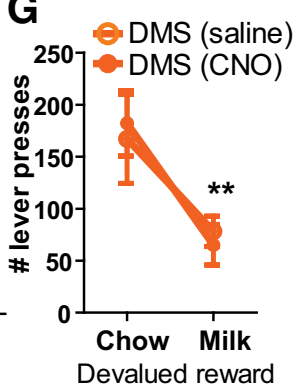

Figure 3. Inhibiting the indirect pathway in either DMS or NAc leads to enhanced motivation and does not affect sensitivity to reward devaluation. $A$, Sagittal section micrograph showing hM4D-mCherry expression in the DMS and GPe of a representative D2-Cre mouse. Scale bar, $1 \mathrm{~mm} . \boldsymbol{B}, \boldsymbol{C}$, Superimposed traces of viral spread from sagittal sections at $\sim 1.4$ and $2.0 \mathrm{~mm}$ right and left of bregma for all animals injected with the AAV5/hSyn-DI0-hM4D-mCherry virus into the DMS. Traces were overlaid onto a diagram of the corresponding sagittal section adapted from Paxinos' mouse brain atlas (Franklin and Paxinos, 2008). D-F, Mice expressing hM4D in indirect-pathway MSNs selectively in the DMS showed enhanced performance in the progressive ratio task of motivation after treatment with CNO compared with saline, measured by survival functions for session duration $(p=0.0054)(\boldsymbol{D})$, breakpoint $(p=0.0043)(\boldsymbol{E})$, and total number of lever presses made in each session $(p=0.0091)(\boldsymbol{F}) . \boldsymbol{G}$, In a test of outcome devaluation, compared with a control condition in which mice were prefed chow, a food that had never been previously associated with lever pressing, mice expressing hM4D in the DMS showed similar decreased rates of pressing after prefeeding with evaporated milk and treatment with CNO or saline (prefeeding: $p=0.0075$; drug: $p=0.9699$ ). $\boldsymbol{H}$, Sagittal section micrograph showing hM4D-mCherry expression in the NAc and VP. Scale bar, $1 \mathrm{~mm}$. $I, J$, Superimposed traces of viral spread from sagittal sections at $\sim 1.1$ and $1.3 \mathrm{~mm}$ right and left of bregma for all animals injected with the AAV5/hSyn-DI0-hM4D-mCherry virus into the NAc. Traces were overlaid onto a diagram of the corresponding sagittal section adapted from Paxinos' mouse brain atlas (Franklin and Paxinos, 2008). $\boldsymbol{K}-\boldsymbol{M}$, Mice expressing hM4D in indirect-pathway MSNs selectively in the NAc showed enhanced performance in the progressive ratio task of motivation after treatment with CNO compared with saline, measured by survival functions for session duration ( $p=0.0641$, statistical trend) $(\boldsymbol{K})$, breakpoint $(p=0.0115)(\boldsymbol{L})$, and total number of lever presses made in each session $(p=0.0232)(\boldsymbol{M}) . \boldsymbol{N}$, Mice expressing hM4D in the NAc were sensitive to reward value in the outcome devaluation task in both drug treatment conditions, as they showed similar decreased rates of pressing after prefeeding with evaporated milk and treatment with CN0 or saline (prefeeding: $p=0.0037$; drug: $p=0.5529$ ). There were no differences in the relative responses to CNO between animals expressing hM4D in indirect-pathway MSNs in the DMS and those expressing hM4D in the NAc, measured by survival functions for session duration $(p=0.7547)(\boldsymbol{D}, \boldsymbol{K})$, breakpoint $(p=0.7766)(\boldsymbol{E}, \boldsymbol{L})$, or total number of lever presses made in each session $(p=0.7237)(\boldsymbol{F}, \boldsymbol{M})$. Data from 8 animals expressing hM4D in the DMS and 9 animals expressing hM4D in the NAc were used to calculate all statistics reported above using a crossover design. Error bars indicate SEM. ${ }^{*} p \leq 0.05,{ }^{* *} p \leq 0.01$.

after drug injection and remained elevated for the remainder of the testing session (Fig. 2L). There were no differences between $\mathrm{D} 2 \mathrm{R}-\mathrm{OE}_{\mathrm{dev}}$ mice and control littermates in their locomotor response to $\mathrm{CNO}\left(F_{(1,22)}=1.388, p=0.2513\right)$ (Fig. $2 L)$.

Inhibiting the indirect pathway in either DMS or NAc leads to enhanced motivation

Medial regions of the striatum have been shown to support incentive motivation in instrumental tasks of reinforcement (Corbit and Balleine, 2011; Hilario et al., 2012; Burton et al., 2015). In the results presented above, we targeted both the DMS and NAc, and it was still unclear whether the DMS or NAc might have been specifically responsible for the effect. We therefore injected Cre-dependent hM4D virus in Drd2-Cre mice bilaterally in either the DMS or NAc selectively. These animals were then trained and tested in the progressive ratio task. In animals injected in the DMS, histology confirmed hM4D expression in the DMS and in axon terminal fields in the GPe (Fig. 3A-C). Acutely activating $\mathrm{G}_{\alpha \mathrm{i}}$ signaling in indirect-pathway MSNs in the DMS enhanced motivation in mice, as they continued responding for longer times (DMS: $\chi_{(1)}^{2}=7.745, p=$ 0.0054; Fig. 3D), had higher breakpoints (DMS: $t_{(7)}=4.147, p=0.0043$; Fig. $3 E$ ), and made a greater number of lever presses (DMS: $t_{(7)}=3.572, p=0.0091$; Fig. $3 F$ ). In animals injected in the NAc, histology confirmed hM4D expression in the NAc and in axon terminal fields in the VP (Fig. 3H-J). Acutely inhibiting indirect-pathway MSNs in the NAc enhanced motivation in mice, as they continued responding for longer times (NAc: $\chi_{(1)}^{2}=3.427, p=0.0641$, statistical trend; Fig. $3 K$ ), had higher breakpoints (NAc: $t_{(8)}=3.261, p=0.0115$; Fig. $3 L$ ), and made a greater number of lever presses (NAc: $t_{(8)}=2.495, p=0.0232$; Fig. $3 M$ ). In some animals of the NAc group, viral injection spread unilaterally to the DMS (Fig. $3 I, J)$. When we analyzed performance in the progressive ratio task of only those mice in which the injection was completely restricted to the NAc, we found it to be enhanced in each individual animal. There were no differences in the relative responses to $\mathrm{CNO}$ between animals expressing hM4D in indirectpathway MSNs in the DMS and those expressing hM4D in the NAc, measured by survival functions for session duration $\left(\chi_{(1)}^{2}=0.09760, p=0.7547\right.$; Fig. $\left.3 D, K\right)$, 
breakpoint $\left(t_{(15)}=0.2889, p=0.7766\right.$; Fig. $\left.3 E, L\right)$, or total number of lever presses made in each session $\left(t_{(15)}=0.3602, p=\right.$ 0.7237; Fig. $3 F, M$ ).

Moreover, as observed for mice expressing hM4D in both DMS and NAc, the response to CNO in mice expressing hM4D separately in each striatal subregion cannot be attributed to a change in response vigor: for each ratio requirement reached by all animals in the study, mice in each group showed similar rates of lever pressing after treatment with $\mathrm{CNO}$ or saline (DMS: $F_{(1,14)}=0.1406, p=0.7126$, saline: $27.30 \pm 9.972$ presses $/ \mathrm{min}$, CNO: $26.71 \pm 4.087$ presses $/ \mathrm{min}, n=8$ mice; NAc: $F_{(1,14)}=$ $0.005455, p=0.9422$, saline: $21.07 \pm 3.881$ presses $/ \mathrm{min}$, CNO: $19.75 \pm 3.183$ presses/min, $n=9$ mice) (data not shown).

We also investigated the contributions of the DMS and NAc to the locomotor effect of acutely decreasing function of the indirect pathway. Both groups displayed increased ambulatory activity after treatment with CNO (DMS: $t_{(7)}=4.041, p=0.0049$, saline: $83.62 \pm 4.125 \mathrm{~cm} / \mathrm{min}, \mathrm{CNO}: 151.2 \pm 19.28 \mathrm{~cm} / \mathrm{min}, n=8$ mice; NAc: $t_{(8)}=5.718, p=0.0004$, saline: $71.81 \pm 5.439 \mathrm{~cm} / \mathrm{min}$, CNO: $139.7 \pm 10.67 \mathrm{~cm} / \mathrm{min}, n=9$ mice) (data not shown).

\section{Inhibiting the indirect pathway in either DMS or NAc does not affect the sensitivity to reward devaluation}

We then tested whether inhibiting indirect-pathway function in DMS or NAc alters the sensitivity to changes in the value of the reward. Since all animals were trained to press a lever to obtain evaporated milk as a food reward, we tested whether devaluation of the reward by prefeeding animals with evaporated milk would decrease their rate of operant responding in extinction trials. We found that, compared with prefeeding with chow, prefeeding with milk resulted in reduced lever pressing after treatment with saline as well as after treatment with $\mathrm{CNO}$ (DMS group: prefeeding: $F_{(1,13)}=10.32, p=0.0075$, drug: $F_{(1,13)}=0.001480, p=$ 0.9699; Bonferroni post hoc tests: $p>0.05$ for chow and milk; NAc group: prefeeding: $F_{(1,14)}=12.10, p=0.0037$, drug: $F_{(1,14)}=0.3697, p=0.5529$; Bonferroni post hoc tests: $p>0.05$ for chow and milk) (Fig. $3 G, N)$. These findings show that activating $G_{\alpha \mathrm{i}}$ signaling in indirect-pathway MSNs in either the DMS or NAc does not affect animals' sensitivity to a change in the value of the reward, suggesting that inhibition of indirect-pathway function does not result in habitual lever pressing or a decreased sensitivity to satiation.

\section{Decreasing function of the indirect pathway energizes behavior at the expense of goal-directed efficiency when a sustained response is required to obtain the goal}

Incentive motivation is thought to consist of two components: a directional and an activational component. The directional component involves selecting the actions most likely to reach a goal. The activational or arousal component regulates the initiation, vigor, and persistence of the action. A change in any or all of these activational components will affect performance on the progressive ratio schedule of reinforcement (Salamone and Correa, 2002; Bailey et al., 2015). Given that inhibiting indirect-pathway function leads to hyperactivity in the open field and enhanced performance in the progressive ratio task, we asked whether this manipulation alters specific activational components of motivation. To this end, we tested D2R-OE $\mathrm{E}_{\mathrm{dev}}$ and control mice expressing hM4D in the indirect pathway of NAc and DMS in the progressive hold-down task. This task requires mice to hold down a lever for progressively longer intervals of time to earn each subsequent reward (Bailey et al., 2015). Both D2R-OE and control mice acquired the task successfully (data not shown). After acute treatment with CNO compared with saline, both genotypes continued to engage in the task for longer times (control: $\chi^{2}=12.02, p=0.005$; D2R-OE $\mathrm{dev}: \chi^{2}=21.23, p<0.0001$; Fig. $4 A$ ). As in the progressive ratio task, they also made more lever presses $\left(F_{\operatorname{drug}(1,21)}=44.82, p<0.0001, F_{\text {genotype }(1,21)}=\right.$ $\left.2.215, p=0.1516, F_{\text {interaction }(1,21)}=1.370, p=0.2549\right)$ (Fig. $4 B$ ). However, in contrast to the progressive ratio task, both genotypes earned fewer rewards after being treated with CNO $\left(F_{\operatorname{drug}(1,21)}=\right.$ 31.92, $p<0.0001, F_{\text {genotype }(1,21)}=0.8983, p=0.3540$, $F_{\text {interaction }(1,21)}=0.8442, p=0.3686$ ) (Fig. 4C). This observation is consistent with reduced efficiency at making longer presses, which we confirmed by calculating the proportion of rewarded presses per hold requirement. This measure decreased for hold requirements $\geq 8.2 \mathrm{~s}$ for $\mathrm{CNO}$ - versus saline-treated mice $\left(F_{(1,21)}\right.$ $=7.080, p=0.0143$ ) (Fig. $4 D)$. Figure $4 E$ shows a plot of the distribution of press durations for all lever presses made on different days of testing by one representative subject. Although this mouse made progressively longer hold-down presses on saline treatment days, it made generally shorter and more frequent presses on days when it was treated with CNO (Fig. 4E). These results suggest that activating $\mathrm{G}_{\alpha \mathrm{i}}$ signaling in indirect-pathway MSNs in the DMS and NAc leads to increased motivation by energizing repeated initiation of the goal-directed action, even when this effect results in decreased efficiency in earning rewards.

\section{Chronic activation of hM4D does not affect motivation in mice and leads to drug tolerance that can be reversed by $48 \mathrm{~h}$ of drug abstinence}

Because neuropsychiatric diseases generally require long-term pharmacological treatment, we investigated whether continuous activation of hM4D receptors in indirect-pathway MSNs in the DMS and NAc also enhances motivation. Chronic CNO treatment did not affect performance of mice expressing hM4D in indirect-pathway MSNs in either DMS or NAc in the progressive ratio task, measured by either session duration (DMS: $\chi^{2}=$ 0.02327, $p=0.8788$; NAc: $\chi^{2}=0.8556, p=0.3550$; Fig. $5 A$ ), number of lever presses (DMS: $t_{(7)}=0.8276, p=0.4352$, NAc: $t_{(8)}=0.5896, p=0.5717$; Figure $5 B$ ), or breakpoint (DMS: $t_{(7)}=$ 0.4952, $p=0.6357$, NAc: $t_{(8)}=0.2526, p=0.8069$; Figure $5 C$ ). Similar lack of effect was also observed for D2R-OE $\mathrm{dev}_{\mathrm{dev}}$ mice or control littermates expressing hM4D in indirect-pathway MSNs in both the DMS and NAc (session duration: control: $\chi^{2}=$ 0.2393, $p=0.6247$, median survival: $19.5 \mathrm{~min}$; $\mathrm{D} 2 \mathrm{R}-\mathrm{OE}_{\mathrm{dev}}: \chi^{2}=$ 3.690, $p=0.2969$, median survival: $21.5 \mathrm{~min}$; number of lever presses: $F_{\operatorname{drug}(1,20)}=1.671, p=0.2108, F_{\text {genotype }(1,20)}=0.01001$, $p=0.9213, F_{\text {interaction }(1,20)}=0.1 .907, p=0.1825$, vehicle: $363.667 \pm 61.667 \mathrm{~min}, \mathrm{CNO}: 256.0 \pm 53.333 \mathrm{~min}, n=6$ mice per group) (data not shown). Importantly, the absence of a CNO effect was not due to the different routes of administration (drinking water vs intraperitoneal injection) or instability of CNO in water or room temperature (data not shown).

We then asked whether animals that are treated with CNO for 2 weeks still exhibit a behavioral response to an acute intraperitoneal injection of CNO. As a control experiment, we found that wild-type animals expressing hM4D in the DMS receiving untreated water (chronic vehicle) responded to acute CNO treatment with increased total number of lever presses $\left(t_{(7)}=3.222\right.$, $p=0.0097$ ) (Fig. 6A) and longer session duration $\left(\chi^{2}=4.719\right.$, $p=0.0314$ ) (Fig. 6B). In contrast, wild-type animals on chronic treatment with $\mathrm{CNO}$ did not exhibit an acute response to the drug injection, measured by total number of lever presses $\left(t_{(7)}=\right.$ 0.4880, $p=0.6405$ ) (Fig. $6 C)$ and session duration $\left(\chi^{2}=\right.$ 

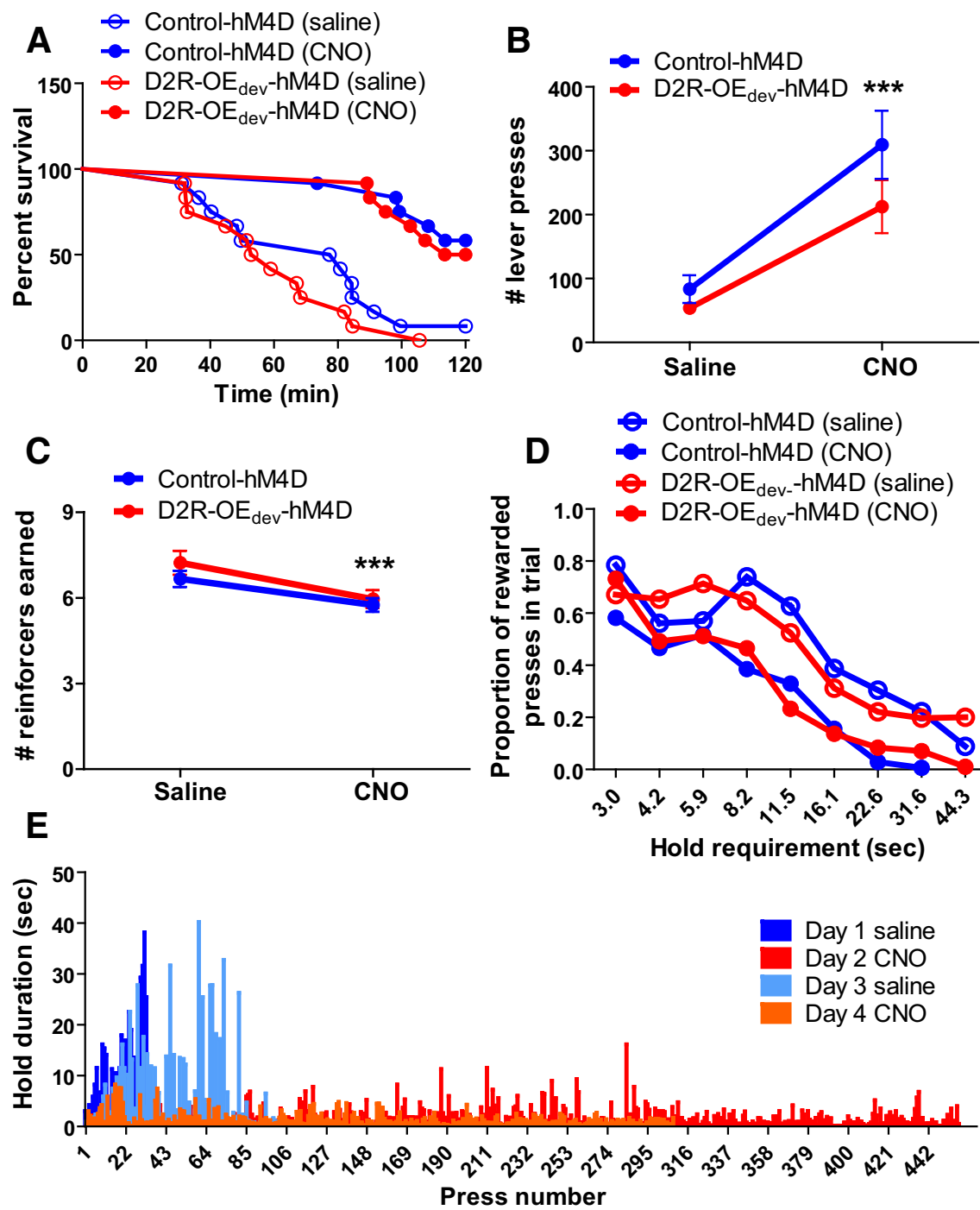

Figure 4. Decreasing function of the indirect pathway energizes behavior at the expense of goal-directed efficiency when a sustained response is required to obtain the goal. $A-D, D 2 R-0 E_{\text {dev }}$ and control littermates expressing $h M 4 D$ in indirect-pathway MSNs show decreased efficiency in the progressive hold-down task after treatment with CNO compared with treatment with saline. Mice of both genotypes continued to respond for longer times when on CNO compared with saline, measured by survival

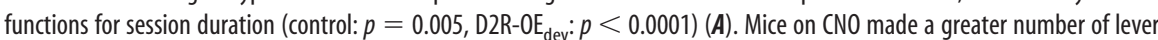
presses $(p<0.0001)(B)$ and earned fewer reinforcers $(p<0.0001)(C)$ in a session compared with saline. For each hold requirement, mice treated with CNO showed lower efficiency in responding compared with treatment with saline, measured by the proportion of rewarded presses $(p=0.0143)(\boldsymbol{D})$. $\boldsymbol{E}$, Distribution of the press duration for all presses made on different days of testing by one representative subject: while this mouse made progressively longer presses on saline treatment days, it made generally shorter presses and a greater number of presses on days when it was treated with CNO. Data from 12 animals per genotype were used to calculate all statistics reported above using a crossover design. Error bars indicate SEM. ${ }^{* *} p \leq 0.001$.

0.01117, $p=0.8931$ ) (Fig. $6 D$ ). Comparable results were obtained for mice expressing hM4D in the NAc (data not shown). These findings show that a response to acute $\mathrm{CNO}$ in the progressive ratio task can no longer be elicited while animals are chronically treated with $\mathrm{CNO}$ in their drinking water.

We then tested the persistence of this tolerance effect after discontinuing chronic CNO treatment. Mice expressing hM4D in the DMS that had been treated with CNO for 2 weeks were taken off the CNO treatment and $48 \mathrm{~h}$ later injected intraperitoneally with $\mathrm{CNO}$ or saline. As expected, mice that were chronically treated with vehicle (control condition) demonstrated enhanced motivation in response to acute $\mathrm{CNO}$, measured by number of lever presses $\left(t_{(7)}=3.261, p=0.0138\right.$ ) (Fig. $6 E$ ) and session duration $\left(\chi^{2}=8.170, p=0.0045\right)$ (Fig. $\left.6 F\right)$. Moreover,
$48 \mathrm{~h}$ off chronic treatment with $\mathrm{CNO}$ was sufficient to re-elicit the behavioral response to acute treatment with $\mathrm{CNO}$ compared with acute treatment with saline (number of lever presses: $t_{(7)}=4.211$, $p=0.0040$; session duration: $\chi^{2}=12.33$, $p=0.0004)($ Fig. 6G,H). Comparable results were obtained for mice expressing hM4D in the NAc (data not shown). And a similar recovery from $\mathrm{CNO}$ tolerance was observed for ambulatory activity in the open field (data not shown). Mice therefore recover their sensitivity to $\mathrm{CNO}$ after $48 \mathrm{~h}$ of drug withdrawal.

\section{Discussion}

Here, we determined whether motivational deficits induced by upregulation of striatal D2Rs starting in early development could be reversed by decreasing function of the indirect pathway in the adult. We found that acute activation of the $\mathrm{G}_{\alpha \mathrm{i}}$-coupled designer receptor hM4D in the indirect pathway increased motivation in $\mathrm{D} 2 \mathrm{R}-\mathrm{OE}_{\mathrm{dev}}$ mice, as well as in control littermates. This effect was due to energized initiation of the behavioral response. Our manipulation facilitated performance when a brief response was required to earn reward but came at the cost of goal-directed efficiency when a response of sustained duration was required to earn the reward. The increase in response initiation was not due to habitual lever pressing because sensitivity to changes in the value of the reward remained intact. It was also not mediated by increased response vigor because the rate of lever pressing during progressive ratio testing was unaltered. Selective manipulation of MSNs in either the DMS or NAc showed that both striatal subregions contribute to this effect on motivation. Furthermore, we also investigated the behavioral effects of chronically decreasing function of the indirect pathway on motivation, and we found that chronic activation of $\mathrm{G}_{\alpha \mathrm{i}}$ signaling in indirect-pathway MSNs leads to a behavioral desensitization that is reversible upon discontinuation of hM4D activation.

Inhibiting indirect-pathway function enhances motivation in $\mathrm{D} 2 \mathrm{R}-\mathrm{OE}_{\mathrm{dev}}$ and wild-type mice

$\mathrm{D} 2 \mathrm{R}-\mathrm{OE}_{\mathrm{dev}}$ mice show deficits in motivation that are associated with enhanced MSN excitability. Because the hM4D receptor has been previously used to decrease MSN excitability in rodents (Ferguson et al., 2011), we inferred that, if hyperexcitability of indirect-pathway MSNs is at the origin of the motivational deficit of $\mathrm{D} 2 \mathrm{R}-\mathrm{OE}_{\mathrm{dev}}$ mice, activating hM4D receptors in this neuronal population would rescue their motivational deficit. However, as both $\mathrm{D} 2 \mathrm{R}-\mathrm{OE}_{\mathrm{dev}}$ and control mice showed increased performance in the progressive ratio task after treatment with $\mathrm{CNO}$, it is 
unclear whether hM4D activation rescued the underlying neuronal mechanism that caused the motivational deficit of $\mathrm{D} 2 \mathrm{R}-\mathrm{OE}_{\mathrm{dev}}$ mice or whether it enhanced motivation by an independent mechanism. Moreover, in our own experiments, we could not detect an effect of hM4D activation on somatic excitability of indirect-pathway neurons (data not shown). But consistent with an inhibitory effect of hM4D activation on synaptic transmission in the GPe, we found that this manipulation disinhibited GPe activity in vivo. We propose that inhibiting function of the indirect pathway may represent a more general strategy to ameliorate deficits in motivation than just rescuing the deficit in $\mathrm{D} 2 \mathrm{R}-\mathrm{OE}_{\mathrm{dev}}$ mice.

\section{Inhibiting indirect-pathway function} energizes the initiation of behavior

Using the progressive hold-down task, we demonstrated that inhibiting function of the indirect pathway energizes the initiation of behavior, which, however, comes at the expense of goal-directed efficiency. In the progressive hold-down task, maximal efficiency requires animals to suppress any tendency to initiate new behaviors to successfully hold down a lever until a reward is obtained. Inhibition of the indirect pathway caused both $\mathrm{D} 2 \mathrm{R}-\mathrm{OE}_{\mathrm{dev}}$ and control mice to continue to engage in this task for longer times. However, acute $\mathrm{CNO}$ treatment also caused animals to make many responses of short duration and thus earn fewer rewards in the progressive hold-down task. These observations suggest that inhibition of the indirect pathway in the NAc and DMS enhances motivation by primarily regulating the readiness to initiate behaviors rather than affecting processes related to the optimal selection of specific behaviors or to processes that regulate the vigor or persistence of actions. This increased tendency to affect initiation of prepotent behavior could account for the effects we observed in both operant tasks and in the open field.

Our results are interesting in light of earlier studies showing that D1R antagonists interferes with the initiation of actions (Choi et al., 2009, 2011). In these studies, pharmacologically induced blockade of D1R function, presumably inhibiting function of the direct pathway, led to impairments of initiation, whereas in our study inhibiting indirect-pathway function led to enhanced action initiation. Together, these results indicate that the initiation of action depends on a balance between activity in both indirect and direct pathways, consistent with previous observations that both pathways are active during the onset of new actions (Cui et al., 2013).

It is possible, however, that the primary consequence of inhibiting indirect-pathway function is not enhanced initiation but a reduction in hold times, which would then lead to a faster reinitiation of responding. This interpretation would be in line with the observation that the D2R antagonist raclopride increases hold times (Fowler and Liou, 1994).

Moreover, although our data are consistent with an increased action initiation, altered sensitivity to reward cannot be fully excluded. Whereas $\mathrm{CNO}$ enhanced the number of lever presses in the progressive ratio task, we did not observe any enhancement of lever pressing in the devaluation task. This may be due to the fact
B
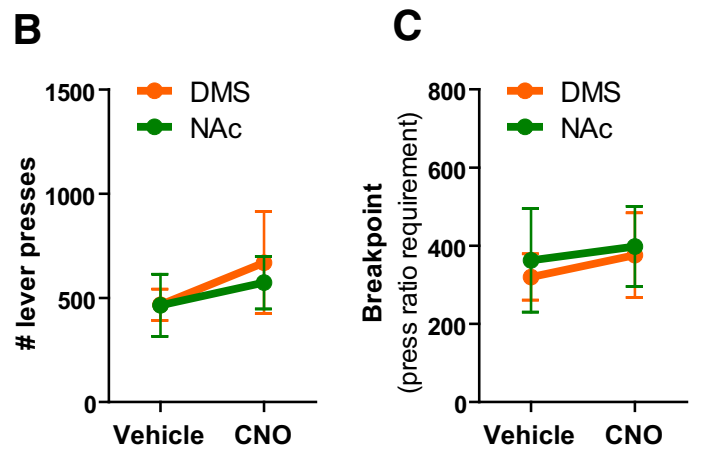

that a lower effort is required during the devaluation task or, alternatively, that no reward is delivered in the devaluation task. Enhanced responding in the progressive ratio task could therefore also be influenced by an enhanced sensitivity to reinforcement.

\section{Inhibiting indirect pathway in both DMS and NAc enhances motivation}

Previous studies have shown that the NAc, and not the DMS, plays a key role in goal-directed behavior by regulating how animals allocate effort to achieve specific outcomes based on the rewarding value of those outcomes (Nowend et al., 2001; Mai et al., 2012). These studies often used instrumental tasks that were inherently different from the progressive ratio task used here. In the latter studies, animals chose between a high-effort action that led to a high-value reward and a low-effort action that led to a low-value reward. Lesioning or antagonizing D1R and D2R function in the NAc made animals less motivated, choosing low-effort actions that led to smaller rewards (Nowend et al., 2001; Mai et al., 2012). It is likely, therefore, that the NAc plays a specific role in effort-related choices. Our findings that acutely decreasing function of the indirect pathway selectively in either the NAc or DMS led to similar enhanced motivation, without affecting outcome devaluation, suggest that both subregions of the striatum work together to regulate at least the initiation of motivated behavior. Consistent with these observations, a number of studies have established a role for the DMS in motivated behavior (Yin et al., 2005b; Shiflett et al., 2010; Hilario et al., 2012). Other behavioral assays of instrumental performance, such as tasks that measure sensitivity to response contingencies or effort/value relationships, may potentially reveal dissociations between the role of the indirect pathway arising from the DMS and NAc in motivation.

\section{Possible therapeutic relevance of inhibiting indirect-pathway function}

The link between initiation of motor behaviors, motivation, and function of the indirect pathway is also relevant for Parkinson's patients who present with both difficulty initiating motor actions and deficits in motivation. In a rodent model of Parkinson's disease using 6-OHDA lesions, animals exhibited a deficit in moti- 


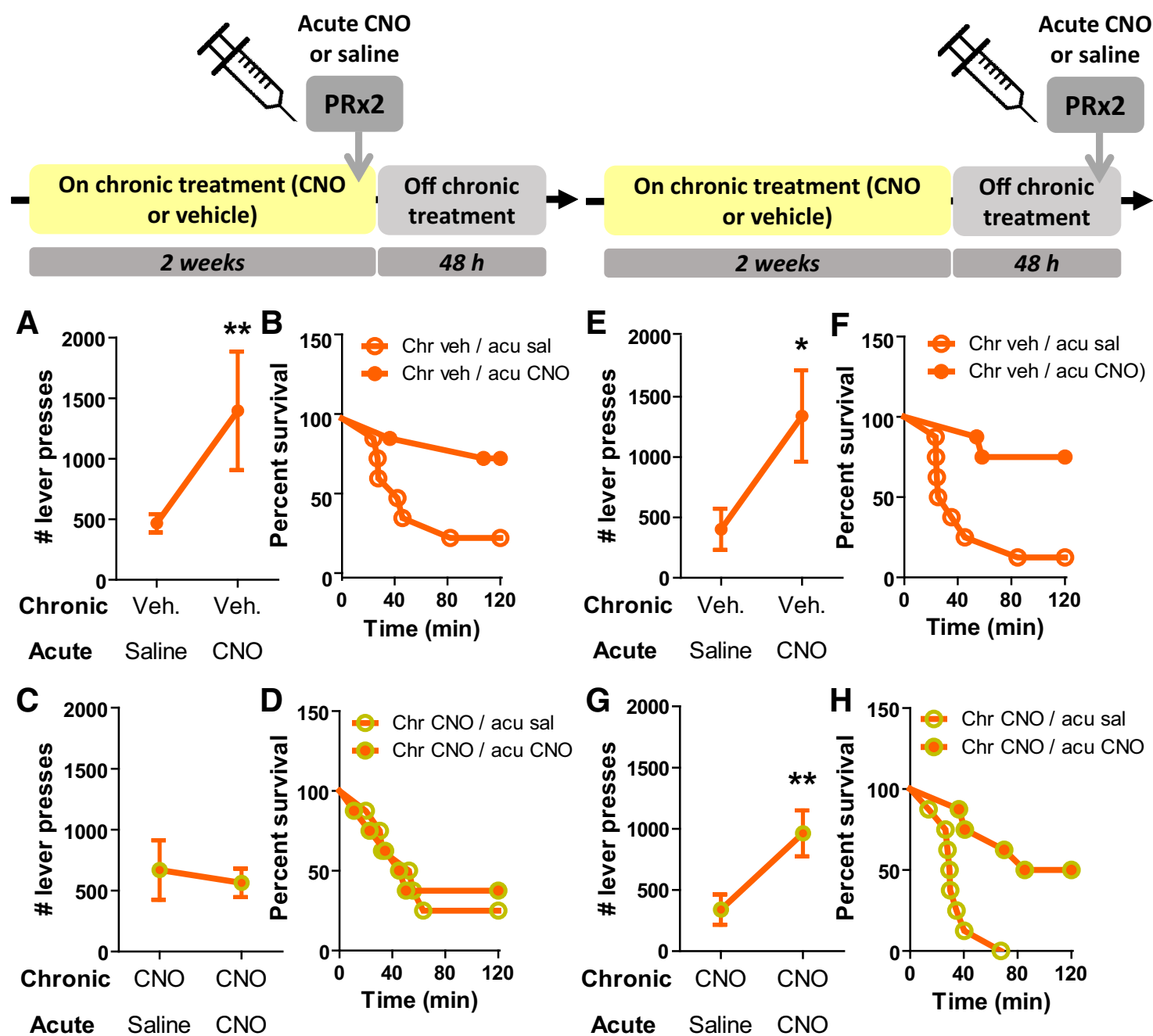

Figure 6. Chronic activation of hM4D does not affect motivation in mice and leads to drug tolerance that can be reversed by $48 \mathrm{~h}$ of drug abstinence. $A, B, D 2$ - $C$ re animals expressing $\mathrm{hM} 4 \mathrm{D}$ in the DMS on the chronic vehicle treatment condition responded to acute CN0 treatment with increased total number of lever presses $(p=0.0097)(\boldsymbol{A})$ and longer session duration $(p=0.0314)(\boldsymbol{B})$ compared with their response to acute saline in the progressive ratio task. $\boldsymbol{C}, \boldsymbol{D}$, When animals were tested in the same task while being treated chronically with $C N 0$, there was no difference in their performance after acute treatment with saline or $(\mathrm{N} 0$, measured by number of lever presses $(p=0.6405)(\boldsymbol{C})$ and session duration $(p=0.8931)(\boldsymbol{D})$. $\boldsymbol{E}, \boldsymbol{F}$, After being taken off chronic treatment for $48 \mathrm{~h}$, the same animals previously treated with vehicle showed enhanced performance in the progressive ratio task in response to acute CNO treatment, measured by total number of lever presses $(p=0.0138)(\boldsymbol{E})$ and session duration $(p=0.0045)(\boldsymbol{F}) . \mathbf{G}, \boldsymbol{H}$, Among animals previously treated with chronic $\mathrm{CN} 0,48 \mathrm{~h}$ off the chronic drug was sufficient to re-elicit a behavioral response to acute treatment with CNO in the progressive ratio task because, under these conditions, mice made more lever presses $(p=0.0040)(\boldsymbol{G})$ and continued to respond for longer times in the task $(p=0.0004)$ (H) compared with their performance after acute treatment with saline. A total of 8 mice expressing hM4D in the DMS were used for these statistical analyses using a crossover design. Error bars indicate SEM. ${ }^{*} p \leq 0.05,{ }^{* *} p \leq 0.01,{ }^{* * *} p \leq 0.001$.

vation that was reversed by a D2R agonist (Favier et al., 2014). Moreover, D2R agonists have also been effective in treating lack of motivation in patients with Parkinson's disease (Thobois et al., 2013). These findings in animals and patients lacking dopamine neurons are interesting because the behavioral effects of D2R activation on striatal MSNs have been difficult to study pharmacologically in the intact BG due to D2 autoreceptors in dopaminergic axon terminals projecting to the striatum (Sesack et al., 1994; Ford, 2014). Consistent with these findings, the behavioral effects demonstrated in the current study using a system that selectively activates $G_{\alpha \mathrm{i}}$ signaling in D2R-positive MSNs suggest that selective therapeutic approaches targeting indirect-pathway function may be useful in treating motivational deficits in Parkinson's disease and other brain disorders. However, our data also suggest that a specific enhancement in the activational component of motivation can come at the cost of goal-directed efficiency, which should be considered when choosing such treatment strategy.
Because brain disorders are chronic and require continuous, long-term pharmacological treatment, we also tested whether chronically inhibiting function of the indirect pathway would also enhance motivation in our experimental system. Surprisingly, we found that chronically activating $G_{\alpha i}$ signaling in indirect-pathway MSNs did not affect motivation or locomotion in mice. One explanation for the lack of behavioral response to chronic treatment is that the mutated $\mathrm{G}_{\alpha \mathrm{i}}$-protein-coupled hM4D receptor became desensitized during chronic $\mathrm{CNO}$ administration. To address this question, we administered an acute intraperitoneal injection of $\mathrm{CNO}$ or saline to mice expressing hM4D in indirect-pathway MSNs, while they were chronically consuming $\mathrm{CNO}$, and found no effect of the injection. We then demonstrated that this behavioral desensitization was not permanent because motivation and locomotion responses to an acute $\mathrm{CNO}$ injection could be re-elicited $48 \mathrm{~h}$ after discontinuing chronic treatment. Although we did not directly address the mechanism of behavioral desensitization, one likely possibility is 
that the $\mathrm{G}_{\alpha \mathrm{i}}$-coupled receptor becomes desensitized due to internalization after chronic stimulation (Gainetdinov et al., 2004). Alternatively, behavioral desensitization may be mediated by circuit-level adaptations. The fast recovery of the response suggests that structural anatomical rewiring may not be required, but the desensitization effect could be mediated by circuit-level plasticity, which is known to occur at shorter timescales (Caroni et al., 2014). Thus, receptor desensitization or circuit adaptations are to be taken into consideration when developing chronic therapies for neuropsychiatric disorders. Our results may explain why drugs that target GPCRs may not improve motivation when taken chronically by patients (Catapano and Manji, 2007).

In conclusion, the present study shows that the indirect pathway is important for regulating response initiation, a process that can be pharmacologically manipulated to increase behavioral activation. However, inhibiting the indirect pathway may also lead to inefficient responding at the cost of reduced reward outcome in situations in which a long duration of action is required to obtain a goal. These findings provide insight into BG function and should inform the development of new treatments for neuropsychiatric disorders with abnormal motivation.

\section{References}

Abi-Dargham A, Rodenhiser J, Printz D, Zea-Ponce Y, Gil R, Kegeles LS, Weiss R, Cooper TB, Mann JJ, Van Heertum RL, Gorman JM, Laruelle M (2000) Increased baseline occupancy of D2 receptors by dopamine in schizophrenia. Proc Natl Acad Sci U S A 97:8104-8109. CrossRef Medline

Albin RL, Young AB, Penney JB (1989) The functional anatomy of basal ganglia disorders. Trends Neurosci 12:366-375. CrossRef Medline

Bailey MR, Jensen G, Taylor K, Mezias C, Williamson C, Silver R, Simpson EH, Balsam PD (2015) A novel strategy for dissecting goal-directed action and arousal components of motivated behavior with a progressive hold-down task. Behav Neurosci 129:269-280. CrossRef Medline

Bock R, Shin JH, Kaplan AR, Dobi A, Markey E, Kramer PF, Gremel CM, Christensen CH, Adrover MF, Alvarez VA (2013) Strengthening the accumbal indirect pathway promotes resilience to compulsive cocaine use. Nat Neurosci 16:632-638. CrossRef Medline

Burton AC, Nakamura K, Roesch MR (2015) From ventral-medial to dorsal-lateral striatum: neural correlates of reward-guided decisionmaking. Neurobiol Learn Mem 117:51-59. CrossRef Medline

Caroni P, Chowdhury A, Lahr M (2014) Synapse rearrangements upon learning: from divergent-sparse connectivity to dedicated sub-circuits. Trends Neurosci 37:604-614. CrossRef Medline

Catapano LA, Manji HK (2007) G protein-coupled receptors in major psychiatric disorders. Biochim Biophys Acta 1768:976-993. CrossRef Medline

Cazorla M, Shegda M, Ramesh B, Harrison NL, Kellendonk C (2012) Striatal D2 receptors regulate dendritic morphology of medium spiny neurons via Kir2 channels. J Neurosci 32:2398-2409. CrossRef Medline

Cazorla M, de Carvalho FD, Chohan MO, Shegda M, Chuhma N, Rayport S, Ahmari SE, Moore H, Kellendonk C (2014) Dopamine D2 receptors regulate the anatomical and functional balance of basal ganglia circuitry. Neuron 81:153-164. CrossRef Medline

Choi WY, Morvan C, Balsam PD, Horvitz JC (2009) Dopamine D1 and D2 antagonist effects on response likelihood and duration. Behav Neurosci 123:1279-1287. CrossRef Medline

Choi WY, Campbell CM, Balsam PD, Horvitz JC (2011) Effects of cortical and striatal dopamine D1 receptor blockade on cued versus noncued behavioral responses. Behav Neurosci 125:705-713. CrossRef Medline

Corbit LH, Balleine BW (2011) The general and outcome-specific forms of Pavlovian-instrumental transfer are differentially mediated by the nucleus accumbens core and shell. J Neurosci 31:11786-11794. CrossRef Medline

Corbit LH, Muir JL, Balleine BW (2001) The role of the nucleus accumbens in instrumental conditioning: evidence of a functional dissociation between accumbens core and shell. J Neurosci 21:3251-3260. Medline

Cui G, Jun SB, Jin X, Pham MD, Vogel SS, Lovinger DM, Costa RM (2013)
Concurrent activation of striatal direct and indirect pathways during action initiation. Nature 494:238-242. CrossRef Medline

Dawson VL, Dawson TM, Wamsley JK (1990) Muscarinic and dopaminergic receptor subtypes on striatal cholinergic interneurons. Brain Res Bull 25:903-912. CrossRef Medline

Drew MR, Simpson EH, Kellendonk C, Herzberg WG, Lipatova O, Fairhurst S, Kandel ER, Malapani C, Balsam PD (2007) Transient overexpression of striatal D2 receptors impairs operant motivation and interval timing. J Neurosci 27:7731-7739. CrossRef Medline

Durieux PF, Schiffmann SN, de Kerchove d'Exaerde A (2012) Differential regulation of motor control and response to dopaminergic drugs by $\mathrm{D} 1 \mathrm{R}$ and $\mathrm{D} 2 \mathrm{R}$ neurons in distinct dorsal striatum subregions. EMBO J 31: 640-653. CrossRef Medline

Favier M, Duran T, Carcenac C, Drui G, Savasta M, Carnicella S (2014) Pramipexole reverses Parkinson's disease-related motivational deficits in rats. Mov Disord 29:912-920. CrossRef Medline

Ferguson SM, Eskenazi D, Ishikawa M, Wanat MJ, Phillips PE, Dong Y, Roth BL, Neumaier JF (2011) Transient neuronal inhibition reveals opposing roles of indirect and direct pathways in sensitization. Nat Neurosci 14: 22-24. CrossRef Medline

Ford CP (2014) The role of D2-autoreceptors in regulating dopamine neuron activity and transmission. Neuroscience 282C:13-22. CrossRef Medline

Fowler SC, Liou JR (1994) Microcatalepsy and disruption of forelimb usage during operant behavior: differences between dopamine D1 ( $\mathrm{SCH}-$ 23390) and D2 (raclopride) antagonists. Psychopharmacology 115: 24-30. CrossRef Medline

Franklin KBJ, Paxinos G (2008) The mouse brain in stereotaxic coordinates. San Diego: Academic.

Fuijyama F, Sohn J, Nakano T, Furuta T, Nakamura KC, Matsuda W, Kaneko $\mathrm{T}$ (2011) Exclusive and common targets of neostriatofugal projections of rat striosome neurons: a single neuron-tracing study using a viral vector. Eur J Neurosci 33:668-677. CrossRef Medline

Gainetdinov RR, Premont RT, Bohn LM, Lefkowitz RJ, Caron MG (2004) Desensitization of $\mathrm{G}$ protein-coupled receptors and neuronal functions. Annu Rev Neurosci 27:107-144. CrossRef Medline

Gallo EF, Salling MC, Feng B, Morón JA, Harrison NL, Javitch JA, Kellendonk C (2015) Upregulation of dopamine D2 receptors in the nucleus accumbens indirect pathway increases locomotion but does not reduce alcohol consumption. Neuropsychopharmacology 40:1609-1618. CrossRef Medline

Gerfen CR, Surmeier DJ (2011) Modulation of striatal projection systems by dopamine. Annu Rev Neurosci 34:441-466. CrossRef Medline

Hilario M, Holloway T, Jin X, Costa RM (2012) Different dorsal striatum circuits mediate action discrimination and action generalization. Eur J Neurosci 35:1105-1114. CrossRef Medline

Howes OD, Kapur S (2009) The dopamine hypothesis of schizophrenia: III. The final common pathway. Schizophr Bull 35:549-562. CrossRef Medline

Kellendonk C, Tronche F, Casanova E, Anlag K, Opherk C, Schütz G (1999) Inducible site-specific recombination in the brain. J Mol Biol 285: 175-182. CrossRef Medline

Kellendonk C, Simpson EH, Polan HJ, Malleret G, Vronskaya S, Winiger V, Moore H, Kandel ER (2006) Transient and selective overexpression of dopamine D2 receptors in the striatum causes persistent abnormalities in prefrontal cortex functioning. Neuron 49:603-615. CrossRef Medline

Kravitz AV, Freeze BS, Parker PR, Kay K, Thwin MT, Deisseroth K, Kreitzer AC (2010) Regulation of parkinsonian motor behaviours by optogenetic control of basal ganglia circuitry. Nature 466:622-626. CrossRef Medline

Kupchik YM, Brown RM, Heinsbroek JA, Lobo MK, Schwartz DJ, Kalivas PW (2015) Coding the direct/indirect pathways by D1 and D2 receptors is not valid for accumbens projections. Nat Neurosci 18:1230-1232. CrossRef Medline

Laruelle M (1998) Imaging dopamine transmission in schizophrenia: a review and meta-analysis. Q J Nucl Med 42:211-221. Medline

Lenz JD, Lobo MK (2013) Optogenetic insights into striatal function and behavior. Behav Brain Res 255:44-54. CrossRef Medline

Lex B, Hauber W (2010) The role of nucleus accumbens dopamine in outcome encoding in instrumental and Pavlovian conditioning. Neurobiol Learn Mem 93:283-290. CrossRef Medline

Mai B, Sommer S, Hauber W (2012) Motivational states influence effort- 
based decision making in rats: the role of dopamine in the nucleus accumbens. Cogn Affect Behav Neurosci 12:74-84. CrossRef Medline

Nowend KL, Arizzi M, Carlson BB, Salamone JD (2001) D1 or D2 antagonism in nucleus accumbens core or dorsomedial shell suppresses lever pressing for food but leads to compensatory increases in chow consumption. Pharmacol Biochem Behav 69:373-382. CrossRef Medline

Pedersen KF, Larsen JP, Alves G, Aarsland D (2009) Prevalence and clinical correlates of apathy in Parkinson's disease: a community-based study. Parkinsonism Relat Disord 15:295-299. CrossRef Medline

Salamone JD (1988) Dopaminergic involvement in activational aspects of motivation: effects of haloperidol on schedule-induced activity, feeding, and foraging in rats. Psychobiology 16:196-206.

Salamone JD, Correa M (2002) Motivational views of reinforcement: implications for understanding the behavioral functions of nucleus accumbens dopamine. Behav Brain Res 137:3-25. CrossRef Medline

Sesack SR, Aoki C, Pickel VM (1994) Ultrastructural localization of D2 receptor-like immunoreactivity in midbrain dopamine neurons and their striatal targets. J Neurosci 14:88-106. Medline

Shiflett MW, Brown RA, Balleine BW (2010) Acquisition and performance of goal-directed instrumental actions depends on ERK signaling in distinct regions of dorsal striatum in rats. J Neurosci 30:2951-2959. CrossRef Medline

Simpson EH, Balsam PD (2015) The behavioral neuroscience of motivation: an overview of concepts, measures, and translational applications. Curr Top Behav Neurosci. Advance online publication. Retrieved Nov 25, 2016. doi: 10.1007/7854_2015_402. CrossRef Medline

Tai LH, Lee AM, Benavidez N, Bonci A, Wilbrecht L (2012) Transient stimulation of distinct subpopulations of striatal neurons mimics changes in action value. Nat Neurosci 15:1281-1289. CrossRef Medline
Thobois S, Ardouin C, Lhommée E, Klinger H, Lagrange C, Xie J, Fraix V, Coelho Braga MC, Hassani R, Kistner A, Juphard A, Seigneuret E, Chabardes S, Mertens P, Polo G, Reilhac A, Costes N, LeBars D, Savasta M, Tremblay L, et al. (2010) Non-motor dopamine withdrawal syndrome after surgery for Parkinson's disease: predictors and underlying mesolimbic denervation. Brain 133:1111-1127. CrossRef Medline

Thobois S, Lhommée E, Klinger H, Ardouin C, Schmitt E, Bichon A, Kistner A, Castrioto A, Xie J, Fraix V, Pelissier P, Chabardes S, Mertens P, Quesada JL, Bosson JL, Pollak P, Broussolle E, Krack P (2013) Parkinsonian apathy responds to dopaminergic stimulation of D2/D3 receptors with piribedil. Brain 136:1568-1577. CrossRef Medline

Tomer R, Goldstein RZ, Wang GJ, Wong C, Volkow ND (2008) Incentive motivation is associated with striatal dopamine asymmetry. Biol Psychol 77:98-101. CrossRef Medline

Volkow ND, Wang GJ, Fowler JS, Thanos PP, Logan J, Gatley SJ, Gifford A, Ding YS, Wong C, Pappas N (2002) Brain DA D2 receptors predict reinforcing effects of stimulants in humans: replication study. Synapse 46 : 79-82. CrossRef Medline

Ward RD, Kellendonk C, Simpson EH, Lipatova O, Drew MR, Fairhurst S, Kandel ER, Balsam PD (2009) Impaired timing precision produced by striatal D2 receptor overexpression is mediated by cognitive and motivational deficits. Behav Neurosci 123:720-730. CrossRef Medline

Yin HH, Knowlton BJ, Balleine BW (2005a) Blockade of NMDA receptors in the dorsomedial striatum prevents action-outcome learning in instrumental conditioning. Eur J Neurosci 22:505-512. CrossRef Medline

Yin HH, Ostlund SB, Knowlton BJ, Balleine BW (2005b) The role of the dorsomedial striatum in instrumental conditioning. Eur J Neurosci 22: 513-523. CrossRef Medline 